\title{
Analyzing high resolution topography for advancing the understanding of mass and energy transfer through landscapes: A review
}

\author{
Paola Passalacqua ${ }^{\mathrm{a}, *}$, Patrick Belmont ${ }^{\mathrm{b}}$, Dennis M. Staley ${ }^{\mathrm{c}}$, Jeffrey D. Simley ${ }^{\mathrm{c}}$, \\ J Ramon Arrowsmith ${ }^{\mathrm{d}}$, Collin A. Bode ${ }^{\mathrm{e}}$, Christopher Crosby ${ }^{\mathrm{f}}$, Stephen B. \\ DeLong ${ }^{g}$, Nancy F. Glenn ${ }^{\mathrm{i}}$, Sara A. Kelly ${ }^{\mathrm{b}}$, Dimitri Lague ${ }^{\mathrm{j}}$, Harish \\ Sangireddy ${ }^{\mathrm{a}}$, Keelin Schaffrath ${ }^{\mathrm{b}}$, David G. Tarboton ${ }^{\mathrm{k}}$, Thad Wasklewicz ${ }^{\mathrm{l}}$, \\ Joseph M. Wheaton ${ }^{\mathrm{b}}$ \\ ${ }^{a}$ Department of Civil, Architectural, and Environmental Engineering and Center for \\ Research in Water Resources, The University of Texas at Austin, 301 E. Dean Keeton St. \\ STOP C1700 Austin, TX 78712-2100, USA \\ ${ }^{b}$ Department of Watershed Sciences, Utah State University, 5210 Old Main Hill, NR 350 \\ Logan, UT 84322-5210, USA \\ ${ }^{c}$ U.S. Geological Survey, Golden CO, USA \\ ${ }^{d}$ School of Earth and Space Exploration, Arizona State University, 1151 S. Forest Ave., \\ Tempe, AZ 85281 USA \\ ${ }^{e}$ Department of Integrative Biology, University of California Berkeley, Valley Life Sciences \\ Bldg 3140, Berkeley CA 94720-3140 USA \\ ${ }^{f}$ UNAVCO, 6350 Nautilus Drive, Boulder, CO 80301-5394 USA \\ ${ }^{g}$ U.S. Geological Survey, 345 Middlefield Road, Menlo Park, CA 94025-3561 USA \\ ${ }^{h}$ Department of Geosciences, Boise State University, 1910 University Drive Boise, ID \\ 83725-1535 USA \\ ${ }^{i}$ Department of Geosciences, Boise State University, 1910 University Drive Boise, ID \\ 83725-1535 USA \\ ${ }^{j}$ Géosciences Rennes, Université Rennes 1, UMR6118 CNRS, Campus de Beaulieu, 35042 \\ Rennes Cedex, France \\ ${ }^{k}$ Department of Civil and Environmental Engineering, Utah State University, 5210 Old \\ Main Hill, NR 350, Logan, UT 84322-5210, USA \\ ${ }^{l}$ Department of Geography, A-204 Brewster Hall, East Carolina University, Greenville, NC \\ 27858, USA
}

\section{Abstract}

The study of mass and energy transfer across landscapes has recently evolved to comprehensive considerations acknowledging the role of biota and humans as geomorphic agents, as well as the importance of small-scale landscape features. A contributing and supporting factor to this evolution is the emergence over the last two decades of technologies able to acquire High Resolution Topography

\footnotetext{
* Corresponding author

Email address: paola@austin.utexas.edu (Paola Passalacqua)
}

Preprint submitted to Earth Science Reviews

April 12, 2015

(C) 2016. This manuscript version is made available under the Elsevier user license http://www.elsevier.com/open-access/userlicense/1.0/ 
(HRT) (meter and sub-meter resolution) data. Landscape features can now be captured at an appropriately fine spatial resolution at which surface processes operate; this has revolutionized the way we study Earth-surface processes.

The wealth of information contained in HRT also presents considerable challenges. For example, selection of the most appropriate type of HRT data for a given application is not trivial. No definitive approach exists for identifying and filtering erroneous or unwanted data, yet inappropriate filtering can create artifacts or eliminate/distort critical features. Estimates of errors and uncertainty are often poorly defined and typically fail to represent the spatial heterogeneity of the dataset, which may introduce bias or error for many analyses. For ease of use, gridded products are typically preferred rather than the more informationrich point cloud representations. Thus many users take advantage of only a fraction of the available data, which has furthermore been subjected to a series of operations often not known or investigated by the user. Lastly, standard HRT analysis work-flows are yet to be established for many popular HRT operations, which has contributed to the limited use of point cloud data.

In this review, we identify key research questions relevant to the Earthsurface processes community within the theme of mass and energy transfer across landscapes and offer guidance on how to identify the most appropriate topographic data type for the analysis of interest. We describe the operations commonly performed from raw data to raster products and we identify key considerations and suggest appropriate work-flows for each, pointing to useful resources and available tools. Future research directions should stimulate further development of tools that take advantage of the wealth of information contained in HRT data and address present and upcoming research needs such as the ability to filter out unwanted data, compute spatially variable estimates of uncertainty and perform multi-scale analyses. While we focus primarily on HRT applications for mass and energy transfer, we envision this review to be relevant beyond the Earth-surface processes community for a much broader range of applications involving the analysis of HRT. 
Keywords: lidar, geomorphic features, change detection, point cloud, InSAR, IfSAR, bathymetry, Structure from Motion, filtering

\section{Introduction}

One of the fundamental principles for understanding Earth-surface processes is conservation (Anderson and Anderson, 2010); the total rate of change of a quantity, such as mass or energy, within a control volume equals the rate of

5 change of the quantity stored within the control volume plus the quantity net outflow across the control surface. Rates of change depend on sources and sinks of the quantity of interest and on spatial gradients in transport rates. Many problems of interest to geomorphologists and hydrologists can be cast in these terms (Kirkby, 1971). Development of a sediment budget of a watershed, for example, requires the identification of sediment sources and sinks, and the understanding of how sediment is transformed and transported from one point of the watershed to another.

The ability to predict water, sediment, and nutrient transfer, map natural hazards, perform a radiation balance, and understand biophysical feedbacks that control landscape form and function is of great value to Earth-surface scientists and natural resources managers. This ability relies on the understanding of how mass and energy are transferred through watersheds and landscapes. Contributions on this topic have populated the geomorphologic and hydrologic literature for over a century (Gilbert and Dutton, 1880; Davis, 1892; Gilbert, 1909; Gilbert and Murphy, 1914; Strahler, 1952; Culling, 1960; Kirkby, 1971; Smith and Bretherton, 1972; Willgoose et al., 1991a,b,c; Anderson, 1994; Howard, 1994; Tucker and Slingerland, 1994, 1997; Dietrich et al., 2003) which also account for the effect of biota and humans on landscapes. A large set of field observations and models, in fact, supports the knowledge that biological productivity affects directly and indirectly landscape evolution (e.g., Drever, 1994; Butler, 1995; Gabet, 2000; Lucas, 2001; Sidle et al., 2001; Bond et al., 2002; Meysman et al., 2006; Yoo et al., 2005; Phillips, 2009; Foufoula-Georgiou et al., 
2010). Humans, long recognized as geomorphic agents (Marsh, 1869, 1882), have now significantly impacted landscapes and their ecosystems (Hooke, 1994, 2000; Foley et al., 2005; Ellis et al., 2006; Montgomery, 2007; Syvitski and Saito, 2007; Wilkinson and McElroy, 2007; Ellis, 2011; Sidle and Ziegler, 2012; Tarolli et al., 2014). Roads, for example, can play an important role in a watershed sediment budget as they constitute a significant source of sediment (Sidle and Ziegler, 2012) and disrupt ecosystem connectivity (Riitters and Wickham, 2003).

The evolution in mass and energy transfer studies is also reflected in mathematical modeling approaches. From the employment of classic mass and energy conservation laws (Eagleson, 1986; Lane, 1998; Trimble, 1999; Dietrich et al., 2003), recent years have also seen the development of nonlocal constitutive laws expressing the material flux at a point (e.g., sediment flux) as a function of the conditions in some neighborhood around this point in space and/or in time (e.g., Bradley et al., 2010; Foufoula-Georgiou et al., 2010; Ganti et al., 2010; Tucker and Bradley, 2010; Foufoula-Georgiou and Passalacqua, 2013; Furbish and Roering, 2013). The nonlocal approach allows incorporating the heterogeneity and complexity typical of geomorphic systems and the wide range of spatial and temporal scales that characterizes geomorphic processes.

Topographic gradients are a key factor in the transport of mass and energy. Whether computed at the location of interest or over a domain of influence as in nonlocal approaches, topographic attributes, such as slope, curvature, and roughness, play a fundamental role in the transport of mass and energy through landscapes. In the past, however, the representation of the Earth-surface was possible only at coarse spatial resolutions (i.e., $\geq 10 \mathrm{~m}$ ). Data collected during the Shuttle Radar Topography Mission (SRTM data), for example, were a major breakthrough in the early 2000s, but are quite coarse (30 $m$ resolution) compared to today's standards. SRTM data do not capture many of the small 55 scale features and perturbations, both natural and anthropogenic, that combine to exhibit significant control over mass and energy transfer. This applies also to the US Geological Survey's National Elevation Dataset that has traditionally only been available at $10 \mathrm{~m}$ and $30 \mathrm{~m}$ resolutions. 
The explosion of availability of high resolution topography (HRT) over the

(Nissen et al., 2012; Oskin et al., 2012; Glennie et al., 2014). The variability and complexity of landscapes, particularly at large scales (Rhoads, 2006) and over time can be fully embraced with HRT data. Preliminary mapping can be performed over vast areas from a personal computer and can be used to identify 85 specific locations of interest to be subsequently field surveyed. The completeness of HRT also offers the opportunity to advance process-understanding through change measurement (e.g., vegetation development, sedimentation, bank erosion) and heterogeneity characterization (e.g., vegetation, rockfall size distribution). 
In addition to these substantial advantages, working with HRT data presents significant challenges. Given that numerous combinations of platforms and techniques for HRT acquisition exist, users often have little basis for determining which platforms are best for their specific application (Bangen et al., 2014). For many applications (e.g., fluvial environments), no single HRT platform or technique paints a complete topographic picture and instead multiple techniques are combined (Williams et al., 2014). Raw HRT data post processing techniques and related parameters are often not known to the earth scientist end-user and frequently not made available from the data provider. What operations are performed on raw data to create a usable point cloud? What further operations are needed to create a Digital Terrain Model (DTM)? Can geomorphic features be extracted automatically and objectively? How does one quantify change over time from point cloud or rasterized data? Despite the rapidly growing availability of HRT data, scientific discovery and applications of HRT data analyses to directly inform natural resource policy and management have been limited. Tools for extracting useful information from HRT data have been developed and new ones are under development, but the Earth Sciences community lacks guiding principles and standard analysis work-flows as well as best practices for determining and reporting HRT data quality. These factors have resulted in a knowledge gap that separates HRT viewers and HRT analysts.

With this review, we wish to reduce this knowledge gap. In the material that follows, we offer an overview of available data types and guidance on how to choose the most appropriate HRT data platform for the application at hand. We identify sources of error and work-flows to account for uncertainty. We discuss the operations that are commonly, or should be, performed in converting raw data to point clouds to raster products and how the analysis of mass and energy transfer through landscapes has changed with HRT data. It is not our goal to provide a comprehensive review of HRT acquisition and HRTbased research, which have been recently provided by Glennie et al. (2013b), Roering et al. (2013), and Tarolli (2014). We also narrow our focus to the anal${ }_{120}$ ysis of mass and energy transfer across landscapes, but many of the ideas and 
tools presented in this review will be relevant to other facets of the Earth-surface processes community and beyond.

The paper is organized in four main sections. The 'Ask' section (Section 2) covers HRT data sources, how to choose the most appropriate data type, critical questions to ask when acquiring a new HRT dataset or attempting to determine the quality of an existing HRT dataset, and key considerations to account for uncertainty. The 'Do' section (Section 3) is focused on the operations performed from raw data to point clouds to raster products, work-flows for feature and change detection, and broad considerations on mass and energy transfer studies with HRT. The 'Next' section (Section 4) explores the next generation of HRT data, opportunities for development of appropriate analysis tools, and needs to further our understanding of mass and energy transfer through landscapes. Finally, we offer guiding principles for HRT analysis in Section 5.

\section{ASK: Considerations for planning HRT acquisition or working with previously collected HRT data}

Use of HRT data poses challenges for the Earth science community; however, these can be mitigated with a fuller understanding of data characteristics, formats, provenance, and by identification of proper tools to measure data quality, manipulate and analyze data and address the scientific question of interest. In this section, we address important factors to consider when acquiring new data, including what should be standard requirements for new data acquisition, whether you are acquiring the HRT data yourself or requesting from a commercial vendor, as well as what information is needed to assess the quality of data previously collected by someone else. We offer an overview of the types of available HRT, their characteristics, and guidance on how to choose the most appropriate HRT for the application at hand. We then discuss sources of uncertainty and present strategies for uncertainty assessment of data and data processing. The main steps to obtain derived products (workable point clouds and rasters) from raw data will be presented in Section 3. 


\subsection{Available platforms and system components}

Lidar sensors have been deployed from both airborne (typically called Airborne Laser Scanning ALS) and ground-based platforms (typically called ground based lidar or Terrestrial Laser Scanning TLS). ALS is the only technique that can 

the main advantage of ALS with respect to other platforms. Conventional lidar systems (airborne and terrestrial) operate in the near infrared (NIR) part of the light spectrum, which is rapidly attenuated or reflected by water and therefore provides limited information in wet areas.

185 Fig. 2 (a)) in small amounts of time (hours). Tripod base (TLS) is instead used when a higher resolution and more flexibility in the scanning angle are needed (Fig. $2(\mathrm{~b})$ ). The spatial extent of TLS is much smaller than ALS (Table. 1, Fig. 1) and the feasible extents vary by instrument (long-range versus shortrange) and geometry of the area of interest.

Vegetation can be very difficult to remove from ALS and TLS data and may in fact be the largest source of uncertainty in locations with moderate to high vegetation density. There are not many comparable alternatives that provide the spatial extent and point density that can be attained with ALS data tripod-based surveying may not be possible.

Bathymetric lidar (green Airborne Laser Scanning gALS) uses the green-blue portion of the light spectrum which can penetrate water. However, even within the green-blue portion of the spectrum, the capability of detecting channel bed topography varies with water depth and turbidity (Glennie et al., 2013b). A 
good rule of thumb is that data will be acquired down to approximately the depth that can be visually seen, although recently developed systems are expected to reach twice the visible depth.

Given that channels are often the most dynamic $1 \%$ of the landscape and 215 play critical roles in mass and energy transfer in landscapes, it may be desirable to utilize sonar instruments to capture bathymetry and subsequently stitch those data into HRT data covering the terrestrial surface. Single-beam SONAR (SBS) and multibeam bathymetric SONAR (MBS) are mounted on boats or on small floating devices (preferred when navigation is limited by shallow water and/or presence of vegetation). The primary advantages of SBS are cost, relatively low (easily manageable) data density and ease of operation in shallow water. SBS surveys tend to be adequate for monitoring relatively large geomorphic change and coarse bathymetric surveys for 1D hydrologic modeling. MBS provides a much higher data density and captures many more of the fine-scale 225 features (ripples, dunes, boulders, etc.), which may or may not be necessary depending on the question at hand. Because of the sparser data density, SBS surveys often require interpolation between survey lines, which can introduce error into the bathymetric dataset. Another emergent bathymetric technology is interferometric sonar, which has the benefits of much wider swath width, lower sensitivity to vessel roll and wave action, and lower cost, compared to MBS.

Synthetic Aperture Radar (SAR) is a class of side-looking radar systems that are deployed from airborne platforms, typically mounted on an aircraft or spacecraft (Doerry and Dickey, 2004; Oliver and Quegan, 2004). SAR systems can create HRT data (with $m$ to $\mathrm{cm}$ precision) using advanced echo timing techniques (Doppler processing). Interferometric SAR (IfSAR or InSAR) uses the parallax (phase shift) in two different SAR images collected at different radar antenna elevation angles to generate a 3D surface with vertical resolution typically less than $1 \mathrm{~m}$. Advantages of SAR include the ability to collect data during the day or night and penetrate weather and dust that might limit other 240 remote sensing techniques.

The latest generation of Very High Resolution (VHR) satellite imagery $(<1$ 
$m$ pixel resolution; e.g., WorldView-2, Pleiades, Geoeye-1) can also be used to reconstruct digital surface models (DSM) down to $1 m$ spatial resolution and vertical accuracy as good as $0.5 \mathrm{~m}$ in the best conditions (Table 1). The current limitations in using SAR and VHR comes from the relatively high level of expertise needed to process the imagery into a high quality surface model.

Recent photogrammetric techniques, such as Structure from Motion (SfM) (James and Robson, 2012) and Multi-View Stereo (MVS), can be mounted on UAVs and represent a low-cost option for acquiring HRT (Fig. 2 (c)). Such approaches require relatively little training and are extremely inexpensive, and thus potentially represent a methodological leap in ad hoc HRT data collection (Fonstad et al., 2013). Point cloud densities with vertical and horizontal error on the order of $\mathrm{cm}$ can be achieved, although the resulting datasets may be subject to large errors due to incorrect flight plans or lens calibration (James and Robson, 2014).

Comprehensive reviews on each platform can be found in the literature, such as Mallet and Bretar (2009), Petrie and Toth (2009c), and Glennie et al. (2013b) (ALS including full waveform), James and Robson (2012) and Westoby et al. (2012) (SfM), Heritage and Hetherington (2007), Petrie and Toth (2009a), Petrie and Toth 260 (2009b), Day et al. (2013a), and Day et al. (2013b) (TLS), Brooks et al. (2013), Glennie et al. (2013a), and Williams et al. (2014) (MLS), Hobi and Ginzler (2012) and Stumpf et al. (2014) (VHR), Bangen et al. (2014) (SBS, MBS), and Wasklewicz et al. (2013) for an overview on ALS, TLS, photogrammetry, and SAR.

\subsection{Sources of uncertainty, error modeling and error propagation}

265 Regardless of the HRT platform, uncertainty assessments of raw HRT data and subsequent post processing into point clouds, terrain and surface models should be completed and reported with any scientific study. For both the investigator and the audience, the most important question to address is whether or not the uncertainty is significant to the question or purposes for which the HRT is being used (Wheaton et al., 2008). The type of assessment and the extent to which one explores uncertainty should be driven by the research question(s) 
one is answering. A comprehensive uncertainty analysis or full error budget can be challenging (Joerg et al., 2012) and is not always necessary. We advocate focusing the uncertainty analysis on whether the signal sought from HRT data and analyses is larger than the noise inherent in the HRT data (i.e., signal to noise ratio; see following sections).

Data inventory and exploration are first steps to an uncertainty assessment. For example, in addition to the point cloud information, are there independent ancillary data such as Ground Control Points (GCPs) of elevation and vegetation heights available? Visual analysis of the data, either in 2D or 3D (with an immersive environment) and ideally with ancillary data such as topographic or vegetation information, may reveal both obvious (e.g., data corduroy) and subtle errors in the data (e.g., power lines confused with tree tops). In addition, assessing the topographic complexity and the distribution and species of vegetation across the site will provide information about the potential spatial distribution and magnitude of uncertainty in the point cloud and/or raster data (Hopkinson et al., 2005; Hodgson et al., 2005; Spaete et al., 2011). This assessment may include parameters such as slope, surface roughness (bare earth and vegetation), and/or vegetation height and cover derived from the point cloud and/or raster data.

\subsubsection{Scope of uncertainties}

The scope of uncertainties with respect to HRT can be overwhelming and a full accounting is beyond the scope of this paper. However, we can usefully identify three primary types of uncertainties specific to HRT data that span the full scope (Table 2): i) positional uncertainties, ii) classification uncertainties, and iii) surface representation uncertainties.

HRT positional uncertainties describe the uncertainty in both the horizontal and vertical location of individual topographic points in a point cloud. The source of positional uncertainties are the sensor's precision and accuracy, the geometry of acquisition (e.g., range and angle of incidence), and the position of the sensor (Lichti and Skaloud, 2010). Mobile and airborne systems require a 
combination of GPS and inertial measurement unit (IMU) systems to position and orient the sensor and yield directly globally georeferenced point clouds. Ground-based surveys from a static position (e.g., TLS or TS) can be kept in a local coordinate system with high accuracy (e.g., using fixed targets) before being globally georeferenced (e.g., by knowing the GPS position of the targets). Beyond the actual precision of the sensors, this difference in georeferencing translates into a position accuracy that is an order of magnitude better for TLS (sub-cm) compared to ALS $(\approx 5-10 \mathrm{~cm})$. Quite importantly, the georeferencing error is unlikely to be spatially uniform due to variations in the quality of the GPS/IMU positioning during a survey (Lichti and Skaloud, 2010) and actual distribution and number of targets in a static TLS survey (e.g., Bae and Lichti, 2008). Data delivered by commercial providers rarely provide the means to propagate the georeferencing errors into a spatially variable uncertainty such that a uniform georeferencing error is systematically used.

Beyond the georeferencing error, error inherent to the instrument (in particular the angular accuracy and range accuracy/precision) and error introduced during calibration (e.g., boresight), it is important to understand that the position uncertainty of any given point obtained by a lidar system (fixed or mobile) will depend on the scanning geometry, that is the range to the ground and the incidence angle (e.g., Schaer et al., 2007; Soudarissanane et al., 2011). In the absence of a simple model to account for these effects, most studies assume a uniform position uncertainty related to instrument error and scanning geometry. For high accuracy requirements it is however possible to filter out points of high incidence angle to only keep the best measurements in the subsequent point cloud analysis (e.g., Schaer et al., 2007). To our knowledge, there is no way at present to directly derive a spatially explicit error model for SfM-derived point clouds. Estimates of the accuracy of SfM point clouds have been based on a comparison with higher quality data (numerous GCPs or lidar) and have shown that the position uncertainty is of the order of 1/1000 the camera distance (e.g., James and Robson, 2012). Recent work has shown that incorrect survey organization can introduce large scale deformation of the surface (James and Robson, 
2014).

HRT classification uncertainties depend on quality of the detection of bare earth and method of classification (see Section 3.2). For simple scenes without vegetation, without objects obstructing the view of the surface (e.g., tripods, people, etc.), and flat ground, no uncertainty is introduced at this stage. However, for more typical cases of interest to Earth scientists, with different types of vegetation (e.g., trees and grass), significant roughness (e.g., debris, pebbles) ${ }^{440}$ and complex topography (e.g., steep slopes, vertical surfaces such as channel banks), the detection and classification of the point cloud into ground and non-ground elements can be difficult and may require significant manual validation/correction. The first issue is to know if the ground has actually been sampled by the sensor, or if vegetation or other objects were obscuring the measurement of the ground. In that case, characterizing uncertainty in ground detection requires an estimate of vegetation height. A second issue is that many algorithms for bare earth detection have been developed for 2.5D geometry typical of ALS surveys (e.g., Sithole and Vosselman, 2004; Tinkham et al., 2011) and can fail when applied in steep landscapes, or cannot be applied on vertical surfaces documented by TLS (e.g., cliffs, overhangs, and undercut river banks) where only 3D methods can be used (Brodu and Lague, 2012). Another issue specific to change detection is the fact that rough surfaces will never be sampled identically by a scanning instrument, which means that a change will always be measured even if the surface was not modified. This change is however not significant when compared to the surface roughness (e.g., Wheaton et al., 2010; Lague et al., 2013). A local measure of point cloud roughness (such as the detrended standard deviation (Brasington et al., 2012)) is thus a first order estimate of the uncertainty in the ground position in the context of change detection. Point density also impacts the quality of bare earth detection as the denser the point cloud, the more likely that one can correctly classify vegetation and ground.

HRT surface representation uncertainties are related to the transformation of the unorganized point cloud into a continuous elevation surface. The most 
commonly used representation is a raster digital elevation model (DEM), but conservative and more sophisticated model of error may be warranted to see if the signal can be detected and if/how the pattern varies spatially. 
A second principle of HRT uncertainty accounting and error estimation is that a more sophisticated model of error cannot reduce the uncertainty, just more accurately quantify it (Wheaton et al., 2010). That is, it makes sense to invest time in a more sophisticated model when there is reason to believe that the data is fundamentally of high enough quality and accuracy to reveal the HRT-derived signal of interest. This is not necessarily known a priori, but general rules of thumb as highlighted in the best case error magnitudes of Table 2 can give some lower plausible bounds on what is possible depending on the survey technique. However, a more accurate estimate of HRT errors may simply highlight locations where the signal is indistinguishable from noise. This in itself may be helpful for identifying primary sources of error worth attempting to constrain or rectify in future HRT data acquisition or post processing, but for any existing HRT dataset or derivative it cannot convert poor quality data to good quality data. For example, if the signal is obscured by noise, considering the classification uncertainty or positional uncertainty in more detail may help identify if fundamental problems exist in the raw data (e.g., GPS positioning was inaccurate) or in what was surveyed (e.g., are there any ground shots in the TLS survey?) that cannot be rectified, or if they may be other problems that more sophisticated post-processing may rectify (e.g., flight line misalignment or incorrect vegetation versus ground classification).

Finally, it is important to remember that the estimation of HRT error needs to be done independently for each survey. Many HRT analyses are based entirely off a single survey, at one point in time, with one acquisition/platform/method. It goes without saying that the uncertainty in subsequent HRT analyses are a function of the errors in that survey. However, some HRT models may be a hybrid product of multiple types of HRT surveys, or a composite of HRT surveys from multiple points in time (e.g., an ALS survey of hillslopes and valley bottom from one point in time with a more recent MBS survey of the channel bathymetry). Similarly, any geomorphic change detection problem involves HRT surveys from at least two points in time, and the subsequent uncertainty will be based on independently estimated errors for each HRT survey 


$$
\sigma_{D o D}=\sqrt{\sigma_{D E M_{o l d}}^{2}+\sigma_{D E M_{n e w}}^{2}}
$$

Below we highlight five situations using HRT data that span from the simplest error modeling to full error budgeting. The examples primarily apply to the estimation of vertical errors in a surface model, but the principles are the same whether describing horizontal or vertical errors for cells in a surface or individual points in a point cloud.

\section{Situations where spatially uniform may be enough}

A spatially uniform error estimate assumes that $\sigma$ is not a function of location and is constant in space. A spatially uniform error assessment may be sufficient where the signal that one aims to obtain is large relative to the uncertainty. As an example, a study in which an ALS dataset is used to differentiate target features on the order of meters, a spatially uniform accounting of the error may be sufficient. In this example, visual examination of the data for offset between flight lines, analyzing independent GCPs of the data, and analyzing the topographic and vegetation complexity may be sufficient to assume the reported error by the vendor (e.g., +/$15 \mathrm{~cm}$ ). Note that spatially uniform error estimates that are derived from independent check point data that span the whole range of conditions surveyed are strongly preferable to those just done in the simplest and easiest conditions (e.g., check points on the airport runway). If independent check points were not surveyed, but the HRT survey overlaps a previous survey, which used the same ground control network and coordinate system, us- 
ing fiducial (or reference) surfaces in areas that have not changed (e.g., bedrock outcrops) can be used as an alternative (Klapinski et al., 2014).

2. Situations where simple zonal spatially uniform may suffice

There are a variety of situations where using a single spatially uniform value to estimate vertical surface representation errors will be overly conservative in some areas and overly liberal in other areas (Wheaton et al., 2008). A simple improvement can come from defining regions (i.e., polygons) within which it is reasonable to assume $\sigma$ is constant. For example, Lane and Chandler (2003) identified differences in $\sigma$ on the basis of whether the surface was wet or dry. Others have differentiated ALS DEM errors on the basis of vegetated or unvegetated. Klapinski et al. (2014) differentiated regions in hybrid HRT surveys on the basis of survey methods and roughness (e.g., TS, MBS - rough, MBS - smooth, ALS).

3. Situations where statistical error models make sense

Statistical error modeling of both surface representation uncertainty and point clouds are possible when HRT point clouds are sufficiently dense to calculate meaningful statistics. Such statistics can be calculated for all the points that fall within a moving window centered on sample points (i.e., point-cloud based), or within a grid cell (i.e., surface representation uncertainty). For elevation statistics to be meaningful, they should be calculated only where 4 or more points exist in the sample window or cell. Typical statistics include zMin, zMax, zMean, zRange and zStdDev. Such statistics can be heavily skewed by local surface slope. Brasington et al. (2012) developed a method to fit a mean surface through each grid cell and then recalculate detrended statistics. For example on a reasonably sloping surface comprised of cobbles and/or boulders, the standard deviation of elevation may be more a reflection of the relief and slope across that cell, whereas the detrended standard deviation is a proxy for the surface roughness. In fact Brasington et al. (2012) found a tight correlation between grain size, surface roughness, and standard deviation. For HRT survey 
methods like TLS, SfM, and MBS, individual point accuracy is generally very high and surface roughness is often the dominant driver of surface representation uncertainties and is a reasonable first cut itself as an error model. Brasington et al. (2012) developed the ToPCAT (Topographic Point Cloud Analysis Tool) to facilitate these calculations.

In very dense point clouds, it is not uncommon to have 100's to 1000's of coincident points (points that have different $z$ 's but share the same $x$ and $y$ coordinates). Hensleigh (2014) used the overlap in MBS boat passes (analogous to ALS flight lines) to calculate coincident points as a proxy for measurement uncertainty.

Another approach to statistical estimation of errors is bootstrapping. Using this approach, an elevation surface is built with some random fraction of the data (e.g., 90\% of points) and the remaining points (e.g., 10\%) are used to calculate residual errors between the interpolated surface and measured points (Wheaton et al., 2008). Those residual error value points can be interpolated to approximate an error surface. The process can be repeated multiple times with different random samples to increase the density of points in the interpolated error surface. Note that the resulting distribution of residual errors is sometimes used to estimate spatially uniform errors across an entire surface or within zones.

4. Situations where more complicated spatially variable error models are warranted

Although the statistical error models described above are spatially variable, there may be other factors important in determining the surface uncertainties than just simple elevation statistics. For example, angle of incidence, footprint size, topographic complexity of the surface, sampling density, positional point quality, and interpolation error may all trump surface roughness as the primary driver of error in certain localities within an HRT survey. In these cases, spatially variable error models are warranted. For these studies, one can expand upon the error analysis above. Assum- 
ing the point cloud data are available, assessing the spatial relationship between slope, roughness, and vegetation height and cover may be necessary. This can be completed by developing statistical relationships between independent GCPs and these parameters, using a machine learning approach such as RandomForest (Breiman, 2001). Milan et al. (2011) reviewed some of the approaches available for estimating spatially variable errors. For example, fuzzy inference systems provide a convenient way of combining multiple lines of evidence and the outputs can be calibrated to independent statistical models of error (Wheaton et al., 2010). All of the above methods are supported in the Wheaton et al. (2010) Geomorphic Change Detection Software (GCD: http: \gcd.joewheaton.org).

5. Situations where full error budgets are warranted

Sometimes, if none of the cases described above applies, full error budgets may be warranted and additional information will be needed. For example, complete metadata, including SBET (Smoothed Best Estimate of Trajectory) information of the data collection, will allow for analysis of error in relation to flight parameters such as scan angle, and use of intensity data to identify the relationship between error and ground/vegetation targets (Glennie, 2007; Streutker et al., 2011). Spatially distributed independent GCPs should be collected and used to estimate the error in different slopes and vegetation types. Perhaps one of the most mature examples of full error budgeting comes from the multi-beam sonar community, where TPE (total propagated error) is used in the CUBE (Combined Uncertainty Bathymetric Estimator) tools (Calder and Mayer, 2003) to estimate uncertainties and minimize user subjectivity when data are cleaned and filtered. The TPE estimates attempt to quantify all sources of errors leading to point-based estimates of uncertainty as well as surfacebased estimates of uncertainties. The TPE estimates frequently result in overly conservative estimates of total error, but they are none-the-less useful in reliably defining the spatial pattern of those errors, their rela- 
tive magnitudes and revealing the key sources. The downside of full error budgeting is that it requires a considerable amount of extra input data that is often not available (with the notable exception of hydrography surveys in MBS). These methods are supported in most of the industrystandard MBS manufacture post-processing software (e.g., HPACK and HYSWEEP: http://www . hypack. com/).

In the context of change detection, simple tests should be performed on various parts of one of the surveys to make sure that the uncertainty model is consistent with the change detection method used. For instance, comparing two different decimations of the same point cloud should not yield a statistically detectable change given the uncertainty estimated locally as a function of point density and point cloud roughness (Lague et al., 2013). These methods are supported in the M3C2 algorithm within the CloudCompare software (http://www.danielgm.net/cc/)

\subsection{Summary of common sources of error in HRT analysis and questions one should ask}

In Table 3 we list several common sources of error in HRT analysis and provide recommendations for each. As seen from the previous sections, there are numerous sources of uncertainty that are commonly unknown to the user. To help designing the acquisition of new HRT data or planning the analysis of existing HRT data, we provide in Box 1 and Box 2 questions that any user should ask prior to the beginning of the project. Information on how to address most of these questions is provided in the sections that follow. Some of these questions are too specific to the project at hand to be properly addressed in this review. We recommend users to collect the information needed to address each question before starting the analysis of data.

\subsection{Metadata and reproducibility of scientific results}

570 New data acquisition should follow basic criteria for data storing and sharing. Specifications on the instrument used for acquisition, point density, horizontal 
and vertical accuracy must be stored with the data as well as information on how the data were further processed (e.g., point cloud decimation and classification). While some vendors prefer to keep this information proprietary and inaccessible, it is fundamental to allow reproducibility of scientific results. Helpful reviews on this topic with specific rules to follow for storing and sharing data have been recently provided by White et al. (2013) and Goodman et al. (2014) and include (i) sharing data; (ii) provide metadata; (iii) provide an unprocessed form of the data; (iv) use standard format; (v) perform basic quality control.

\section{DO: Working effectively with HRT data, from raw point clouds to usable data and derivative products}

In this section we discuss research questions of interest to the understanding of how mass and energy are transferred through landscapes and how their analysis has changed with the availability of HRT data. We also discuss important considerations in data processing, including segmentation and filtering, and present general work-flows for feature detection and change detection, which are among the most recurrent operations performed on HRT data. While we refrain from listing available software for each operation (as software is in constant evolution), we refer the reader to the OpenTopography Tool Registry where an updated list of available tools is maintained as well as comments and feedback from the tool users (http://www.opentopography.org/).

\subsection{Science with HRT data}

Viewing HRT as simply a higher resolution version of its coarser predecessors (e.g., $30 \mathrm{~m}$ SRTM data) greatly understates the value of these data for two primary reasons. First, HRT is typically collected at a resolution that permits identification and measurement of the fine-scaled features that inform our understanding of the rates and mechanisms of eco-hydro-geomorphological and earthquake processes. The fact that fine-scaled features can be resolved, changes our approach for analysis and calls for a suite of new techniques and tools for 

yond the bare earth surface elevations (e.g., above ground vegetation density, variability in surface reflectance). Such information can be immensely useful for characterization of the landscape and modeling Earth surface processes.

\subsubsection{HRT provides new approaches to answer fundamental questions}

In the material that follows, we discuss some high level questions currently being pursued by the Earth Surface and Critical Zone communities and discuss how HRT provides opportunities for entirely new approaches to answer these questions.

\section{How are mass and energy transported through landscapes?}

This question encompasses a wide range of studies, from understanding stress and strain fields in tectonically active environments (Frankel and Dolan, 2007; Oskin et al., 2012), to using HRT-derived canopy models to estimate radiative transfer (Lefsky et al., 2002; Vierling et al., 2008; Morsdorf et al., 2009), to constraining sediment, carbon and nutrient budgets and predicting fluxes at the reach or watershed scale (Paola et al., 2006; Belmont et al., 2011; Hudak et al., 2012; Tarolli et al., 2012). Regardless of the specific application, HRT substantially enhances our capacity to answer this question by offering precise quantification of critical features distributed throughout a large spatial domain (e.g., geometry and location of fault scarps, tree canopy, channel heads, river banks, detention basins, see Pike et al. (2009)). Directing budgeting of mass redistribution provides constraints on the magnitude and spatial patterns of geomorphic and ecologic processes. Further, HRT provides a much more detailed and reliable boundary condition for eco-hydro-morphodynamic models, especially insofar as it allows direct coupling with the built environment (Priestnall et al., 2000) and explicit representation of surface roughness (typically dominated by vegetation) (McKean and Roering, 2004; Glenn et al., 2006; Cavalli et al., 2008; McKean et al., 2014), which, for example, has 
allowed for vast improvement in flood inundation prediction (NRC, 2007).

Since HRT allows users to derive higher dimensional information about the surface (e.g., surface cover, roughness), it provides an opportunity to directly link hydraulics, geomorphology, and ecology. In this way, HRT improves the accuracy, spatial extent and response time for hazard assessment and risk mitigation, as well as restoration and conservation planning (Farrell et al., 2013). In cases where it is not feasible or desirable to include all of the detailed information in a model, HRT provides a basis for upscaling localized measurements and generating sub-grid scale parameterizations (Casas et al., 2010; Helbig and Lowe, 2012; Ganti et al., 2012). For many such applications, it is useful to utilize 3D point cloud data to retain information about the above-ground features.

2. What are the patterns on the Earth's surface that can inform our understanding of ecologic, hydrologic, and geomorphic processes and coupling thereof?

Understanding how topography and biota are organized at the micro-, meso-, and macro-scales has been a long standing question in Earth surface science (e.g., Gilbert and Dutton, 1880; Dietrich and Perron, 2006; NRC, 2010). Quantifying the organization of landscape features brings us one step closer to understanding the mechanisms of landscape change (Chase, 1992; Roering, 2008; Hilley and Arrowsmith, 2008; Perron et al., 2009; Roering et al., 2010). Certain features can only be represented and measured accurately/precisely at HRT scales. Therefore, we have only recently acquired the capability to answer this question over large spatial scales. For example, HRT provides a more detailed representation of micro-climates and micro-habitats and a bridge between atmospheric boundary layer and highly localized features/characteristics (e.g., temperature, soil moisture, snow depth) (Molotch et al., 2004; Galewsky et al., 2008; Galewsky, 2009; Deems et al., 2013). HRT data also allows for coupled 3D mapping and modeling of vegetation, hydrology, and topography 
(Ivanov et al., 2008) and in some cases captures the influence/signature of bioturbation (e.g., plants, gophers) (Yoo et al., 2011; Reed and Amundson, 2012; Hugenholtz et al., 2013). Lastly, HRT allows for direct identification and quantification of human imprints on the landscape, permitting distinction between the effects of natural and anthropogenic processes (Passalacqua et al., 2012).

3. How do processes in one location influence processes or rates in another part of the landscape?

One of the most intriguing opportunities presented by HRT data is the ability to predict non-localized effects of processes (Anderson et al., 2012). For example, initiation of a landslide near a ridge crest is likely to cause deposition of a slug of sediment in the valley bottom. Bank erosion at one or many individual locations throughout a watershed is likely to influence turbidity and sediment flux at the mouth of the watershed. Such predictions can only be reliable if the critical features can be identified and the transport mechanisms between the points of interest are known. HRT provides a new mechanism for satisfying the inputs needed for detailed models of mass and energy transfer and takes us a step closer to robust spatially-distributed modeling over large domains.

Improved algorithms to quantify landscape topology and conduct ensemble feature mensuration enable analysis of spatial relationships, from simple metrics such as distance, height, and volume to more complex evaluations of feature proximity and transport pathways (Huang et al., 2011; May et al., 2013; Tomer et al., 2013). Such analyses require the ability to recognize discrete objects whose scale may range between slightly larger than the data resolution and something smaller than the extent of the entire dataset. 


\subsubsection{Fully utilizing HRT requires new approaches, tools, and techniques}

The fact that in HRT we can resolve many of the fine-scale features that are critical for eco-hydro-geomorphic processes changes our analytical approach and demands a new set of tools and techniques. HRT contains an immense amount of information, much of which is not easily extracted with conventional tools. The analysis challenges shift from relatively simple operations performed either on individual pixels or the entire dataset, to the realm of image processing, where the richness of the image can be deconstructed into more meaningful components and manipulated accordingly. For example, coarse topographic datasets that have been prevalent for the past few decades were limited to evaluating macro-scale features, such as basin hypsometry, slope and relief, using pixel-based approaches. Watershed and channel network delineation could only be automated using algorithms that mapped pixel-to-pixel paths of steepest descent and channel heads would be somewhat arbitrarily located at some average/uniform value of upstream contributing area. Small order channels were not identifiable and the boundaries of large channels were poorly resolved. The presence of fine-scaled features in the HRT landscape does not entirely circumvent the need for such approaches, but does open the door to entirely new approaches that are able to take advantage of the wealth of information provided by HRT.

For example, preservation of sharp landscape features, those which are characterized as abrupt changes in topography (e.g., streambanks or fresh fault scarps), requires the use of anisotropic filters (such as nonlinear filters) for cleaning and analysis of HRT. Conventional topographic filters (e.g., Gaussian) have a tendency to diffuse or altogether eliminate such features (Passalacqua et al., 2010b). Another important shift in tools and techniques between conventional topography data and HRT is the use of object-based image (Bian, 2007; Blaschke, 2010). Object-based techniques have been used extensively since the 1980s and 1990s in the industrial and 
medical fields, but have only recently emerged as useful tools for Earth surface science, as the resolution of satellite imagery and topographic datasets has come to exceed the scale of many of the objects, or features, of interest. While it is not the goal of this paper to comprehensively review all of these emerging approaches, it is important to acknowledge their growing use.

Some common object based techniques include segmentation, edge-detection, and feature extraction (Alharthy and Bethel, 2002; Suárez et al., 2005; Brennan and Webster, 2006). Segmentation involves identification of distinct objects by one or more homogeneous criteria in one or more dimensions of feature space. Clearly, objects exist across a variety of scales in HRT, and so segmentation often requires a multi-scale analysis (Hay et al., 2001; Burnett and Blaschke, 2003; Hay et al., 2003; Schmidt and Andrew, 2005; Brodu and Lague, 2012). Other techniques, such as artificial neural networks (Nguyen et al., 2005; Priestnall et al., 2000), fuzzy set methods (Schmidt and Hewitt, 2004; Cao et al., 2011; Hofmann et al., 2011; Hamedianfar et al., 2014), genetic algorithms (Li et al., 2013; Garcia-Gutierrez et al., 2014), machine learning (Zhao et al., 2008, 2011; Gleason and Im, 2012b,a), and support vector machines (Mountrakis et al., 2011; Zhao et al., 2011; Brodu and Lague, 2012) also show great promise to represent discrete features within complex and heterogeneous environments, but applications of such approaches for HRT analysis have been relatively few. Such approaches can greatly expand our capacity to extract useful information from HRT and we thus expect them to become more prevalent in the near future.

\subsection{Getting the data right: From raw to derivative products}

Currently, the vast majority of HRT users begin their analysis work-flows with a gridded product (i.e., DEM) that has previously been subjected to extensive cleaning and filtering and perhaps manual editing (Fisher, 1997). In some cases this is an appropriate starting point for the task at hand, although users should 
be aware of the operations previously performed on the data and associated potential for bias/error, as discussed above. In other cases users may start from this point because upstream versions of the data (raw, classified, or filtered point cloud) are not made available from the data provider, a situation that is becoming less common as vendors and users recognize the value of such data. In yet other cases, many users simply start with the gridded dataset because the common software packages are ill-equipped to deal with point cloud data, or are perceived to require an unwarranted investment of time and effort to utilize. However, tools for cleaning and analyzing point clouds have been improved considerably and, for a variety of applications, the general HRT analysis community has much to gain by beginning their analysis workflow further upstream.

In the material that follows, we cover the operations that are commonly performed from raw data to the creation of derivative products (such as usable point cloud and DEM). Users should require specifics on these operations from the data providers. If new HRT are collected, this information should be compiled and released with the data to facilitate data reuse and reproducibility of scientific results and allow for problems to be rectified in the future as tools for data cleaning and interpolation are improved.

\subsubsection{Georeferencing}

During the georeferencing operation raw data are converted from a local coordinate frame to a geodetic coordinate frame using direct and indirect methods.

Direct methods imply that geodetic coordinates have been collected and assigned to positions on the ground at the time of data acquisition. A terrestrial example is ground-based rtkGPS surveying where topographic points are assigned $x, y, z$ coordinates in real time. Accuracy of such surveys is greatly enhanced when users post-process the data to obtain differentially corrected static GPS measurements. This can be achieved using, for example, the Online Positioning User Service (OPUS) to tie GPS positions collected using an antenna and local base station to the U.S. National Spatial Reference System from nearby 775 Continuously Operating Reference Stations (http://www.ngs.noaa.gov/OPUS/). 
Similar post-processing tools are freely available from a variety of other sources on the web.

Aerial and mobile direct methods are based on the exterior orientation of the sensor relative to the Earth, which can be obtained using GPS and an Internal Navigation System (INS) (Legat, 2006). Geodetic coordinates of positions in the scene are extrapolated from sensor $x-y$ positions and altitudes. This method is most common for ALS and mobile mapping systems as well as stereo-photogrammetry flown by a manned-aircraft.

Sensors, such as cameras or lasers, fixed to UAVs typically do not have onboard navigation systems sufficient for accurate geodetic positioning. Therefore, indirect georeferencing methods that rely on GCPs are common. GCPs are on-the-ground features (natural or artificial) with known coordinates that are identifiable in the collected point cloud or imagery. Typically, the positions of GCPs are surveyed close to the time of data acquisition using GPS. Georeferencing occurs after data acquisition and can be performed easily in common spatial data programs. Both error and distortion need to be considered when applying spline and polynomial georeferencing transformations.

The georeferencing operation for SfM is discussed in the next section as part of the work-flow from raw data to PC generation. For a discussion on the uncertainty associated with georeferencing see Section 2.3.1. We refer the reader to Shan and Toth (2009), Vosselmann and Maas (2010), and Renslow (2012) for further reading on georeferencing.

\subsubsection{Processing raw data to create a usable point cloud}

In some cases it may be required to combine multiple point clouds into a single point cloud, for example in HRT surveys with point clouds obtained from multiple positions on a landscape. This requires bringing multiple point clouds into the same coordinate system, which may be global or local. These point clouds may be from the same HRT platform or from some combination of ALS acquisition, multiple TLS scans, sonar and/or cameras. Merging these point clouds into a unified dataset is achieved through a registration operation performed by 
either relying on points common to multiple clouds (minimum 3 points shared) or setting up targets during the acquisition that can then be used as reference points during the registration operation (some targets can reoccupy exactly the same position during subsequent surveys for high accuracy local georeferencing (Lague et al., 2013)). In natural scenes the latter approach is preferred as it is commonly difficult to identify common points in multiple clouds and surfaces are generally rough which reduces the accuracy of cloud matching techniques (e.g., Schurch et al., 2011; Lague et al., 2013) (unlike engineering applications where features such as structure corners can be used). A lack of common targets can significantly diminish the quality of the data acquired.

In the case of SfM, camera pose and scene geometry are reconstructed simultaneously using the automatic identification of recurrent features in multiple images that have been taken from different angles (Snavely, 2008; Westoby et al., 2012). Although only 3 images per recurrent feature are needed, it is usually recommended to take as many photographs as possible. The point cloud is created in a relative 'image-space' coordinate system. GCPs or physical targets are commonly employed to align the 'image-space' to an 'object-space' coordinate system. The georefencing operation consists of a Helmert Transformation (7 parameters: 1 scale parameter, 3 translation parameters, and 3 rotation parameters) (Turner et al., 2012). Example applications can be found in Westoby et al. (2012), James and Robson (2012), Javernick et al. (2014), and Johnson et al. (2014).

\subsubsection{Point cloud processing, filtering, and classification}

Once the point cloud has been created, several processing operations may be needed before analysis of the point cloud or creation of raster products can be performed. These operations are performed to reduce the size of the point cloud, distinguish ground points from off-ground points, and classify the point cloud into homogeneous portions.

No matter what the data source is, the generated point cloud can be extremely dense. In these cases the number of points often needs to be reduced 
in order to analyze the point cloud. This operation is called decimation. Procedures for decimation include point removal, refinement, and cloud segmentation approaches (Wasklewicz et al., 2013).

Filtering and classification are needed to distinguish ground and off-ground 840 points and further classify the off-ground points. There are 4 main categories of filtering approaches (Sithole and Vosselman, 2004; Pfeifer and Mandlburger, 2009) and they are different in the assumption they make about the structure of the ground points: (i) morphological filters (often slope-based), (ii) progressive densification filters starting from seeds (e.g., lowest points), (iii) surface-based filters (progressive removal of points that do not fit the surface model), (iv) segmentation and clustering (operates within homogeneous segments rather than individual points). Many of these filters operate directly on the point cloud, but others require gridding to take full advantage of image processing techniques (e.g., segmentation). Sithole and Vosselman (2004) report results for a filter comparison on 12 different landscapes and concluded that while all filters are successful in landscapes with low complexity level, the presence of urban structures or steepness influenced the performance of the filters resulting in surface-based filters (filters that rely on a parameterization of the local surface and an above buffer within which ground points are expected to be found) being more successful than others. As noted by Pfeifer and Mandlburger (2009), when this analysis was performed segmentation strategies had not been fully developed yet, while they have been found particularly successful in landscapes modified by humans. Further work by Meng et al. (2010) identified three types of terrain for which filtering algorithms do not work optimally: (i) rough terrains or landscapes with discontinuous slopes, (ii) areas with dense vegetation where the laser cannot penetrate sufficiently, and (iii) areas with short vegetation.

The classification of the point cloud, including vegetation classification, can be one of the most critical operations, particularly in natural and complex landscapes due to the multi-scale nature of the features present. The method proposed by Brodu and Lague (2012) exploits this aspect by probing the surface with spheres of varying diameter, achieving accuracy $>98 \%$ in distinguishing, 
for example, vegetation from ground points and classifying a mountain stream in several classes (vegetation, rock, gravel, water surface). Other vegetation classification approaches have been proposed by Streutker and Glenn (2006), specifically for arid landscapes, and by Evans and Hudak (2007) (the multiscale curvature algorithm MCC designed for high biomass areas). The two latter methods were compared by Tinkham et al. (2011) in a semi-arid landscape. The authors found both methods accurate and suggested specific applications for each.

Information on which decimation, filtering, and classification operations were performed on the point cloud should always be required from the data provider and reported when distributing the collected data.

The operations needed to create a raster and derived raster products are covered in the next section. Before presenting this material, we note that many HRT analyses can (and should) be performed directly on the point cloud. Gridded data are often perceived as the more 'convenient' or easy option to users. Point clouds are more difficult to analyze and are seen as less intuitive than gridded data. These suppositions are further supported by the limitations of commonly used geospatial software, such as ArcGIS, which are so far limited when it comes to point cloud analysis tools. There are, however, many advantages in working directly with the point cloud and it should not be discarded too early. The further into a work-flow the point cloud is carried leads to preservation of the 3D point uncertainty, greater control on $2 \mathrm{D}$ products and multidimensional analysis, and a congruent representation of field data collection. Point clouds offer opportunities for the exploration and extraction of more detailed information (e.g., vegetation classification (Brodu and Lague, 2012)) and higher level modeling (segmentation, textures, machine learning), while also achieving accurate estimates of geometric properties of the 3D environment, particularly relevant to the estimation of $3 \mathrm{D}$ change and $3 \mathrm{D}$ oriented deformation measurements (e.g., Teza et al., 2007; Nissen et al., 2012; Lague et al., 2013). Gridding data involves interpolation which reduces the information originally contained 
in the point cloud.

\subsubsection{Raster generation and derived raster products}

Interpolation algorithms are applied to estimate unknown elevation from elevation data at known location. This operation may be needed to obtain a gridded surface or interpolate over regions that present shadows or data voids to limit their effect on the final gridded surface. It may also be necessary to change the resolution of the raster for the application at hand.

Commonly used interpolation approaches can be distinguished into three categories (Wasklewicz et al., 2013): (i) local neighborhood (e.g., nearest neighbors, inverse distance, creation of Triangular Irregular Network (TIN)), (ii) geostatistical methods (rely on the spatial correlation structure; kriging), and (iii) spline methods (e.g., thin plate spline). Each method has its strengths and weaknesses and an appropriate range of applicability (Chaplot et al., 2006;

Erdogan, 2009; Heritage and Large, 2009), although differences among interpolation approaches are reduced with increasing point density. Interpolation and estimation errors are associated to each approach (Wheaton et al., 2010).

Raster users need to carefully consider the sources of uncertainty mentioned in Section 2.3 as they affect DEMs (Fisher and Tate, 2006) and derived topographic attributes (Sofia et al., 2013).

\subsubsection{Filtering rasters to remove small scale variability and enhance features} of interest

No matter what the specific analysis entails, operations involving derivatives should be performed after small scale variability (e.g., due to local terrain roughness or to vegetation removal operations) has been removed and features of interest enhanced (Passalacqua et al., 2010a,b). Several filters have been proposed in the literature, most of which have been developed within the image processing community. The most common options include Gaussian filtering, nonlinear Perona-Malik filtering, and Wiener filtering.

Gaussian filtering is most often used to smooth noise from data with the 
aid of a spatially uniform smoothing operation. The scale of the features removed depends on the size of the kernel employed for smoothing. The wider the standard deviation of the kernel, the coarser the filtered landscape will be. Considering as an example a high resolution DEM $h_{0}(x, y): R^{2} \rightarrow R$, the filtered landscape $h(x, y, t)$ is obtained through a convolution operation with a Gaussian filter $G(x, y ; t)$ of standard deviation $t$ :

$$
h(x, y, t)=h_{0}(x, y) * G(x, y ; t)
$$

where the Gaussian kernel of standard deviation $t$ is defined as:

$$
G_{x, y, t}(u, v)=\frac{1}{2 \pi t} \exp \left[-\frac{(u-x)^{2}+(v-y)^{2}}{2 t}\right]
$$

The employment of Gaussian filtering is at the core of the channel network extraction method proposed by Lashermes et al. (2007) which uses the convolution with the first and second derivative of the Gaussian to calculate landscape slope and curvature on regularized gridded data.

A feature of Gaussian filtering that may be problematic is the lack of feature localization; the filter is spatially uniform resulting in landscapes uniformly diffused in all directions. This can be problematic in landscapes containing sharp features (e.g., fault scarps, stream banks, roads, etc.) as illustrated by Passalacqua et al. (2010a) (see Fig. 3) and Passalacqua et al. (2010b), who proposed the use of a nonlinear (anisotropic) filter (Perona and Malik, 1990; Catté et al., 1992) able to achieve preferential smoothing of the landscape:

$$
\partial_{t} h(x, y, t)=\nabla \cdot[p(|\nabla h|) \nabla h]
$$

where the edge-stopping function $p(\cdot)$ allows preferential smoothing of small scale variability and enhancement of features of interest. In the application of Passalacqua et al. (2010a), the edge-stopping function has the form:

$$
p(|\nabla h|)=\frac{1}{1+(|\nabla h| / \lambda)^{2}}
$$


Locations with gradients smaller than $\lambda$ are smoothed out, while locations with gradients above $\lambda$ are enhanced. The parameter $\lambda$ is computed as the 90th quantile of the probability density function (pdf) of the elevation gradients (Passalacqua et al., 2010a). The main advantage of the Perona-Malik filter is the capability of enhancing features of interest, while preserving feature localization and removing small scale variability.

The Wiener filter (Wiener, 1949) distinguishes small scale noise from other image features based on the analysis of a radially averaged power spectrum. Its use was recently proposed by Pelletier (2013) to smooth small scale variability in elevation data. The filter operates in the frequency domain through a transfer function defined as:

$$
\Phi(\nu)=\frac{|H(\nu)|^{2}}{|H(\nu)|^{2}+|N(\nu)|^{2}}
$$

where $|H(\nu)|^{2}$ represents the spectrum of the signal and $|N(\nu)|^{2}$ the spectrum of noise, determined by fitting the radially averaged power spectrum of the landscape for lower and higher frequencies. At low frequencies, where $|H(\nu)|^{2}>|N(\nu)|^{2}$, the transfer function $\Phi(\nu)$ is approximately equal to 1 and no modification is made to the data, while at high frequencies, where $|H(\nu)|^{2}<<|N(\nu)|^{2}$, the amplitude of the noise is reduced in a measure proportional to noise to signal amplitude ratio. The main advantage of the Wiener filter

965 is that if the spectrum is fitted correctly, the appropriate smoothing threshold emerges from the data itself.

\subsection{HRT analysis work-flows}

We focus on two operations commonly performed on HRT data: feature extraction (the identification of geomorphic features from a data set acquired at a certain time), and change detection (the quantification of differences between data sets acquired at different times). These are two of the most common and mature analyses attempted with HRT and are presented as examples for similar work-flows that might be developed to standardize other HRT analysis practices. 


\subsubsection{Feature extraction work-flow}

3D point clouds simply sample the entire exposed surface, while all science and engineering applications require the extraction or identification of specific features represented by a sub-set of points within these data. The feature identification work-flow (Fig. 4) begins with the point cloud and the question of

Sofia et al., 2011; Pelletier, 2013), channel morphology (Passalacqua et al., 2012;

Fisher et al., 2013), fluvial terraces (Stout and Belmont, 2014), landslides (Booth et al., 
2009; Roering et al., 2009; Tarolli et al., 2012), river bed and floodplain morphology (Marcus and Fonstad, 2010; Belmont, 2011), and vegetation characteristics (Lefsky et al., 2002; Brandtberg, 2007; Breidenbach et al., 2010; Gleason and Im, 2012b,a).

\subsubsection{Change detection work-flow}

The change detection work-flow starts with a distinction of the type of geometric change of interest (Fig. 5). As discussed above, the two datasets must be similarly georeferenced and uncertainty in each dataset must be quantified to develop an error model that would be used to report the most probable real change. In the case of ground movements displacing topographic features (e.g., landsliding, earthquakes), change can be captured as a 2D-3D displacement field, while when interested in geomorphic processes changing topographic features (e.g., bank erosion, patterns of erosion and deposition), change can be quantified in terms of distance and volume. In all cases, the analysis starts with point cloud data acquired at different epochs that capture the change of interest (e.g., before and after an event). After removal of vegetation and other erroneous points, a 2D-3D displacement field can be obtained directly with a 3D piecewise Iterative Closest Point (ICP) operation (Besl and McKay, 1992; Teza et al., 2007; Nissen et al., 2012), point cloud cross-correlation (Borsa and Minster, 2012), or with 2D correlation techniques (PIV) applied to a 2.5D DTM (Aryal et al., 2012; Mukoyama, 2012). Distance and volume can be quantified directly with a 3D cloud to cloud distance calculation (Lague et al., 2013), or with cloud to mesh comparisons (Rosser et al., 2005; Day et al., 2013a), or vertical subtraction of gridded data (Lane and Chandler, 2003; Wheaton et al., 2010; Schurch et al., 2011; Wheaton et al., 2013; Pelletier and Orem, 2014).

For change detection completed on regularized (gridded) data, one additional requirement is to ensure that the two grids have the same resolution and are concurrent and orthogonal. This means that each pixel being differenced shares the same center point. Operations based on meshed or gridded data are simple to run, but can result in a reduction of accuracy and resolution that should be 
evaluated with respect to the amplitude and spatial characteristics of the to-

pographic signal to be detected (see Section 2.3). In general, for high accuracy application in complex environments, point cloud based methods are more suitable. However, these methods are still in their infancy and key building blocks are still missing (e.g., simple volume computation directly on 3D point clouds).

As HRT is increasingly collected, standards and best practices have improved. Legacy data, or the dataset collected first in time, have likely been collected under different standards and using different practices. These data may contain errors and subsequently produce systematic errors, especially in a differencing analysis. Glennie et al. (2014) describe legacy data issues and a near-field earthquake displacement example for which they used original GPS/IMU and laser measurement data to recalibrate. When those data are not available, others have tried to match some kind of surface or infrastructure in overlapping areas to calculate the alignment (Bretar et al., 2004; Alka, 2010). Another technique used local slope and local elevation difference between adjacent points in the overlap area to more accurately re-align flightlines (Streutker et al., 2011). Others have corrected the final product (a differential DEM in both cases) using a fast Fourier transform filter (Goodwell, 2014).

\section{NEXT: Learning from the present and directions of further devel- opment}

This is an important time for HRT research; technology supporting HRT acquisition has seen major developments in the last two decades resulting in the current availability of significant amounts of data. Numerous papers based on the analysis of HRT data have been published up to present, corresponding to an increased understanding of mass and energy transfer through landscapes and of Earth-surface processes in general. From the identification of landscape characteristic scales, to earthquake assessment, to landslide dynamics, the availability of HRT has advanced scientific understanding of Earth-surface processes in terms of both static and dynamic processes. Notably, these scientific ad- 
vancements have been accompanied by the development and release of broadly applicable open source tools. Sharing open source software requires the commitment of the scientist to overcome several challenges (Easterbrook, 2014) to benefit the community at large.

Too often, however, data analysis tools are not integrated in the same platforms used for visualization, favoring a net separation between a large number of HRT viewers, and a much smaller number of HRT analysts that actively manipulate and query the data in more sophisticated and quantitative ways and develop new open source analysis tools. Development of a framework that supports visualization while facilitating higher level filtering, segmentation, and analysis is needed. Given the immense amount of multi-scale information contained in HRT and the challenges involved in manipulating such large datasets, the HRT community has much to gain by implementing practices and standardized work-flows that have been developed by the image processing and Big Data analytics communities, among others.

HRT data represent the common ground among a variety of disciplines; the atmospheric, surface, biological, anthropogenic, and subsurface processes communities all rely on these data (Paola et al., 2006; Reinhardt et al., 2010). We can thus think of HRT as an interdisciplinary means for achieving a deeper understanding of Earth-surface processes and as a platform to facilitate collaboration across disciplines (Bond et al., 2007). Training of students, researchers, and practitioners has to continue and further develop along this direction to make sure computational, technological, scientific, and engineering aspects of HRT analysis are taught across disciplines. Research centers such as the NSF-funded OpenTopography, National Center for Earth-Surface Dynamics (NCED), and the network of Water, Sustainability and Climate (WSC) and Critical Zone Observatories (CZO) have facilitated an interdisciplinary approach to research and education, including the collection and distribution of HRT data, the development of open source software, and the organization of training workshops and summer schools for junior scientists.

As we witness the development of newer technologies such as mobile li- 
dar, photon counting, hyperspectral lidar, and bathymetric lidar (Glennie et al., 2013b), we note that challenges posed by current technologies still have to be overcome. For example, better acquisition of multi-temporal data is needed for accurate differential topography analysis. The El Mayor Cucapah 2010 earthquake is an important event for which pre- and post-event lidar data are available (Oskin et al., 2012) and pre-event data required re-processing to improve the estimation of coseismic surface displacement (Glennie et al., 2014). Nissen et al. (2014) applied topographic differencing on Japanese HRT to characterize two M6-7 earthquakes in Japan to produce new understanding of near-field coseismic deformation. However, the coverage was limited to just a few $\mathrm{km}^{2}$.

Community standards are still not identified creating considerable problems for data and tools sharing. While existing groups and resources (e.g., NSF SI2, NSF ISEES, OpenTopography, GitHUB, Figshare, HydroShare, CSDMS) have worked significantly in this direction, the effort has to be embraced by the community at large and a broader swath of researchers must be trained to use and further develop such tools. We need to achieve better understanding of the multi-scale dynamics at finer spatial and temporal scales with broader extent. At the global scale we still rely on coarser resolution data such as SRTM; increased access to HRT data globally should be promoted.

As the availability of full waveform hyperspectral, bathymetric, photon counting data becomes common (Glennie et al., 2013b), tools are needed to take 1115 advantage of these data sets and integrate HRT data collected on multiple platforms. The point cloud community has a strong basis to build from (e.g., CloudCompare http://www.danielgm.net/cc/ and http://pointclouds.org/), but more documentation and further development are needed.

HRT can also be fundamental for tool and model testing. The development of sets of examples and applications would be particularly useful to show the performance of existing and new tools on the same landscape. As such, we see the need to identify a set of benchmarking examples to be used for testing models and tools. HRT represent the perfect source for such benchmarking examples, but specific landscapes need to be identified for each modeling task (e.g., sedi- 
local to where students are would substantially enhance the integration of HRT and field-based educational resources.

\section{Conclusions: Guiding principles for HRT analysis}

As we look forward to the next decade of HRT technology development and

1. Promote an environment conducive to data intensive exploration. Existing examples are Hubble Space Telescope, EarthScope, and NEON. This will favor unanticipated and broader uses of the data; 
2. Distribute open and well documented data. This is very important for

gratefully acknowledge support from the National Science Foundation (grants CAREER/EAR-1350336, GSS/BCS-1063228, and FESD/EAR-1135427 to PP; ENG-1209448 to PB; EAR-1225810 to JRA). Comments from the Editor, Paolo Tarolli, Francis Rengers, and an anonymous reviewer have helped improve this 1175

\section{References}

Alharthy A, Bethel J. Heuristic filtering and 3d feature extraction from LIDAR data. In: Proc. ISPRS Comm. III Symp. Photogramm. Comput. Vis. 2002. p. 29-34. 

registration of surfaces by $3 \mathrm{D}$ least squares matching. Photogramm Eng Rem S 2009;76:307-18. doi:10.14358/PERS.76.3.307.

Alka D. Co-registration of surfaces by 3D least squares matching. Photogramm Eng Rem S 2010;76:307-18. doi:10.14358/PERS.76.3.307.

Anderson RS. Evolution of the santa cruz mountains, california, through tectonic growth and geomorphic decay. J Geophys Res 1994;99 (20):161-74.

Anderson RS, Anderson SP. Geomorphology: The Mechanics and Chemistry of Landscapes. Cambridge, UK: Cambridge University Press, 2010. 640 pp.

Anderson SP, Anderson RS, Tucker GE. Landscape scale linkages in critical zone evolution. Comptes Rendus Geoscience 2012;344(11):586-96.

Aryal A, Brooks BA, Reid ME, Bawden GW, Pawlak GR. Displacement fields from point cloud data: Application of particle imaging velocimetry to landslide geodesy. J Geophys Res 2012;117:F01029. doi:10.1029/2011JF002161.

Bae K, Lichti DD. A method for automated registration of unorganised point clouds. ISPRS J Photogramm 2008;63(1):36-54.

Bangen SG, Wheaton JM, Bouwes N, Bouwes B, Jordan C. A methodological intercomparison of topographic survey techniques for characterizing wadeable streams and rivers. Geomorphology 2014;206:343-61.

Belmont P. Floodplain width adjustments in response to rapid baselevel fall and knickpoint migration. Geomorphology 2011;128:92-102.

Belmont P, Gran KB, Schottler S, Wilcock PR, Day SS, Jennings C, Lauer JW, Viparelli E, Willenbring JK, Engstrom DR, Parker G. Large shift in source of fine sediment in the Upper Mississippi River. Env Sci Tech 2011;45:880418810.

1205

Besl PJ, McKay ND. A method for registration of 3D shapes. IEEE T Pattern Anal 1992;14(2):239-56. 
Bian L. Object-oriented representation of environmental phenomena: Is everything best represented as an object? Ann Assoc Am Geogr 2007;97(2):267-81.

Blaschke T. Object based image analysis for remote sensing. ISPRS J Photogramm 2010;65:2-16. doi:10.1016/j.isprsjprs.2009.06.004.

Bond BJ, Jones JA, Moore G, Phillips N, Post D, McDonnell JJ. The zone of vegetation influence on baseflow revealed by diel patterns of streamflow and vegetation water use in a headwater basin. Hydrol Process 2002;16:1671-7. doi:10.1002/hyp. 5022.

Bond CE, Shipton ZK, Jones RR, Butler RWH, Gibbs A. Knowledge transfer in a digital world: Field data acquisition, uncertainty, visualization, and data management. Geosphere 2007;3(6):568-76.

Booth A, Roering JJ, Perron T. Automated landslide mapping using spectral analysis and high-resolution topographic data: Puget sound lowlands, washington, and portland hills, oregon. Geomorphology 2009;109:132-47.

Borsa A, Minster JB. Rapid determination of near-fault earthquake deformation using differential lidar. Bull Seismol Soc Am 2012;102:1335-47.

Bowen ZH, Waltermire RG. Evaluation of light detection and ranging (Lidar) for measuring river corridor topography. J Am Water Res Assoc 2002;38:33-41.

Bradley DN, Tucker GE, Benson DA. Fractional dispersion in a sand bed river. J Geophys Res 2010;115:F00A09. doi:10.1029/2009JF001268.

Brandtberg T. Classifying individual tree species under leaf-off and leaf-on conditions using airborne lidar. ISPRS J Photogramm 2007;61:325-40.

Brasington J, Langham J, Rumsby B. Methodological sensitivity of morphomet1230 ric estimates of coarse fluvial sediment transport. Geomorphology 2003;53(34):299-316. doi:10 .1016/S0169-555X (02) 00320-3. 
Brasington J, Vericat D, Rychkov I. Modeling river bed morphology, roughness, and surface sedimentology using high resolution terrestrial laser scanning. Water Resour Res 2012;48:W11519. doi:10.1029/2012WR012223.

Breidenbach J, Naesset E, Lien V, Gobakken T, Solberg S. Prediction of species specific forest inventory attributes using a nonparametric semi-individual tree crown approach basd on fused airborne laser scanning and multispectral data. Remote Sens Environ 2010;114:911-24.

Breiman L. Random forests. Mach Learn 2001;45:5-32.

Brennan R, Webster TL. Object-oriented land cover classification of lidarderived surfaces. Ca J Remote Sensing 2006;32(2):162-72.

Bretar F, Pierrot-Deseilligny M, Roux M. Solving the strip adjustment problem of 3d airborne lidar data. In: IEEE International Geoscience and Remote Sensing Symposium. 2004. p. 4734-7. doi:10.1109/IGARSS. 2004.1370216.

Brodu N, Lague D. 3D Terrestrial LiDAR classification of complex natural scenes using a multi-scale dimensionality criterion: applications in geomorphology. ISPRS J Photogramm 2012;68:121-34. doi:10.1016/j.isprsjprs.2012.01.006.

Brooks B, Glennie CL, Hudnut K, Ericksen T, Hauser D. Mobile laser scanning applied to the Earth Sciences. EOS 2013;94(36):313-5.

Burnett C, Blaschke T. A multi-scale segmentation/object relationship modelling methodology for landscape analysis. Ecol Model 2003;168:233-49.

Butler DR. Zoogeomorphology: Animals as geomorphic agents. New York: Cambridge University Press, 1995. 239 p.

Calder BR, Mayer LA. Automatic processing of high-rate, high-density multibeam echosounder data. Geochem Geophy Geosy 2003;4(6):1048. doi:10.1029/2002GC000486. 
Cao Y, Zhao H, Li N, Wei H. Land-cover classification by airborne LIDAR data fused with aerial optical images. In: Multi-Platform/Multi-Sensor Remote Sensing and Mapping (M2RSM),. 2011. p. 1-6.

Casas A, Lane SN, Yu D, Benito G. A method for parameterising roughness and topographic sub-grid scale effects in hydraulic modelling from LiDAR data. Hydrol Earth Syst Sci 2010;14:1567-79. doi:10.5194/hess-14-1567-2010.

Catté F, Lions PL, Morel JM, Coll T. Image selective smoothing and edge detection by nonlinear diffusion. SIAM J Numer Anal 1992;29 (1):182-93.

Cavalli M, Tarolli P, Marchi L, Fontana GD. The effectiveness of airborne lidar data in the recognition of channel bed morphology. Catena 2008;73:249-60. doi:1016/j . catena. 2007.11.001.

Chaplot V, Darboux F, Bourennane H, Leguédois S, Silvera N, Phachomphon K. Accuracy of interpolation techniques for the derivation of digital elevation models in relation to landform types and data density. Geomorphology 2006;77:126-41. doi:10.1016/j .geomorph.2005.12 .010.

Chase C. Fluvial landsculpting and the fractal dimension of topography. Geomorphology 1992;5:39-57.

Culling W. Analytical theory of erosion. J Geol 1960;68:336-44.

Davis WM. The convex profile of badland divides. Science 1892;20:245.

Day SS, Gran KB, Belmont P, Wawrzyniec T. Measuring bluff erosion part 1: terrestrial laser scanning methods for change detection. Earth Surf Proc Land 2013a;38:1055-67. doi:10.1002/esp. 3353.

Day SS, Gran KB, Belmont P, Wawrzyniec T. Measuring bluff erosion part 2: pairing aerial photographs and terrestrial laser scanning to create a watershed scale sediment budget. Earth Surf Proc Land 2013b;38:1068-82. doi:10.1002/esp. 3359 . 
Deems JS, Painter TH, Finnegan DC. Lidar measurement of snow depth: a review. J Glaciology 2013;59(215):467-79.

Dietrich W, Bellugi D, Heimsath A, Roering J, Sklar L, Stock J. Geomorphic transport laws for predicting landscape form and dynamics. In: Prediction in Geomorphology, Geophysical Monograph Series (edited by P. Wilcock and R. Iverson). Washington D.C.: AGU; 2003. p. 103-23.

Dietrich W, Perron JT. The search for a topographic signature of life. Nature 2006;439(7075):411-8.

Doerry AW, Dickey FM. Synthetic aperture radar. Opt Photonics News 2004;15(11):28-33.

Drever JI. The effect of land plants on weathering rates of silicate minerals. Geochimica et Cosmochimica Acta 1994;58:2325-32. doi:10.1016/0016-7037(94)90013-2.

Eagleson PS. The emergence of global-scale hydrology. Water Resour Res 1986;22(9):6S-14S.

Easterbrook SM. Open code for open science? Nat Geosci 2014;7:779-81. doi:10.1038/ngeo2283.

Ellis EC. Anthropogenic transformation of the terrestrial biosphere. Phil TRans R Soc A 2011;369:1010-35.

Ellis EC, Wang H, Xiao H, Peng K, Liu XP, Li SC, Ouyang H, Cheng X, Yang LZ. Measuring long-term ecological changes in densely populated landscapes using current and historical high resolution imagery. Remote Sens Environ 2006;100:457-73.

Erdogan S. A comparison of interpolation methods for producing digital elevation models at the field scale. Earth Surf Process Landforms 2009;34:366-76. doi:10.1002/esp. 1731. 
Erwin SO, Schmidt JC, Wheaton JM, Wilcock PR. Closing a sediment budget for a reconfigured reach of the Provo River, Utah, United States. Water Resour Res 2012;48:W10512. doi:10.1029/2011WR011035.

Evans JS, Hudak AT. A multiscale curvature algorithm for classifying discrete return lidar in forested environments. IEEE Trans Geosci Remote Sens 2007;45:1029-38. doi:doi:10.1109/TGRS . 2006.890412.

Farrell SL, Collier BA, Skow KL, Long AM, Campomizzi AJ, Morrison ML, Hays KB, Wilkins RN. Using Lidar-derived vegetation metrics for highresolution, species distribution models for conservation planning. Ecosphere 2013;4(3):art42. doi:10.1890/ES12-000352.1.

${ }_{1320}$ Fisher GB, Bookhagen B, Amos CB. Channel planform geometry and slopes from freely available high-spatial resolution imagery and DEM fusion: Implications for channel width scalings, erosion proxies, and fluvial signatures in tectonically active landscapes. Geomorphology 2013;194:46-56. doi:10.1016/j.geomorph.2013.04.011.

${ }_{1325}$ Fisher P. The pixel: a snare and a delusion. Int J Rem Sens 1997;18(3):679-85.

Fisher PF, Tate NJ. Causes and consenquences of error in digital elevation models. Prog Phys Geog 2006;30:467-89. doi:10.1191/0309133306pp492ra.

Foley JA, DeFries R, Asner GP, Barford C, Bonan G, Carpenter SR. Global consequences of land use. Science 2005;309:570-4.

${ }_{1330}$ Fonstad MA, Dietrich JT, Courville BC, Jensen JL, Carbonneau PE. Topographic structure from motion: a new development in photogrammetric measurement. Earth Surf Process Landforms 2013;38:421-30. doi:10.1002/esp. 3366 .

Foufoula-Georgiou E, Ganti V, Dietrich WE. A non-local theory for 1335 sediment transport on hillslopes. J Geophys Res 2010;115:F00A16. doi:10.1029/2009JF001280. 
Foufoula-Georgiou E, Passalacqua P. Nonlocal transport theories in geomorphology: mathematical modeling of broad scales of motion. In: Shroder J, Baas ACW, editors. Treatise on Geomorphology. San Diego, CA: Academic Press; volume 2; 2013. p. 98-116.

Frankel KL, Dolan JF. Characterizing arid region alluvial fan surface roughness with airborne laser swath mapping digital topographic data. J Geophys Res Earth Surf 2007;112:F02025. doi:10.1029/2006JF000644.

Furbish DJ, Roering JJ. Sediment disentrainment and the concept of local versus nonlocal transport on hillslopes. J Geophys Res Earth Surf 2013;118:937-52. doi:10.1002/jgrf.20071.

Gabet EJ. Gopher bioturbation: Field evidence for non-linear hillslope diffusion. Earth Surface Processes and Landforms 2000;25:1419-28.

Galewsky J. Rain shadow development during the growth of mountain ranges: An atmospheric dynamics perspective. J Geophys Res Earth Surf (2003-2012) 2009;114(F1):F01018. doi:10.1029/2008JF001085.

Galewsky J, Roe G, Anderson R, Meyer G, Flowers G. Climate Over Landscapes: Workshop on Atmospheric Sciences and Surface Processes; Boulder, Colorado, 13 October 2007. EOS 2008;89(16):151.

Gangodagamage C, Belmont P, Foufoula-Georgiou E. Revisiting scaling laws in river basins: New considerations across hillslope and fluvial regimes. Water Resour Res 2011;47:W07508. doi:10.1029/2010WR009252.

Gangodagamage C, Foufoula-Georgiou E, Belmont P. River basin organization around the mainstem: Self-similarity in tributary branching and the incremental area function. J Geophys Res-Earth 2014;in press.

Ganti V, Meerschaert MM, Foufoula-Georgiou E, Viparelli E, Parker G. Normal and anomalous diffusion of gravel tracer particles in rivers. J Geophys Res 2010;115:F00A12. doi:10 .1029/2008JF001222. 
Ganti V, Passalacqua P, Foufoula-Georgiou E. A subgrid scale closure for nonlinear hillslope sediment transport models. J Geophys Res-Earth (2003-2012) $2012 ; 117(\mathrm{~F} 2)$.

Garcia-Gutierrez J, Gonzalez-Ferreiro E, Riquelme-Santos JC, Miranda D, Dieguez-Aranda U, Navarro-Cerillo RM. Evolutionary feature selection to estimate forest stand variables using LiDAR. Int J Appl Earth Obs 2014;26:11931.

Gilbert GK. The complexity of hilltops. J Geol 1909;17:344-50.

Gilbert GK, Dutton CE. Report on the Geology of the Henry Mountains (Utah). Technical Report; U.S. Geological Survey; 1880.

Gilbert GK, Murphy EC. The transportation of debris by running water. Technical Report; U.S. Geological Survey; 1914.

Gleason CJ, Im J. Forest biomass estimation from airborne LiDAR data using machine learning approaches. Remote Sens Environ 2012a;125:80-91. doi:10.1016/j.rse.2012.07.006.

Gleason CJ, Im J. A fusion approach for tree crown delineation from LiDAR data. Photogramm Eng Rem S 2012b;78:679-92.

Glenn NF, Streutker DR, Chadwick DJ, Tahckray GD, Dorsch SJ. Analysis of lidar-derived topography information for characterizing and differentiating landslide morphology and activity. Geomorphology 2006;73:131-48.

Glennie CL. Rigorous 3D error analysis of kinematic scanning LIDAR systems. J Geodesy 2007;1:147-57. doi:10.1515/JAG. 2007.

Glennie CL, Brooks B, Ericksen T, Hauser D, Hudnut K, Foster J, Avery J. Compact multipurpose mobile laser scanning system - Initial tests and results. Remote Sens 2013a;5:521-38. doi:10.3390/rs5020521. 
Glennie CL, Carter WE, Shresta RL, Dietrich WE. Geodetic imaging with airborne LiDAR: the Earth's surface revealed. Rep Prog Phys 2013b;76:086801. doi:10.1088/0034-4885/76/8/086801.

Glennie CL, Hinojosa-Corona A, Nissen E, Kusari A, Oskin ME, Arrowsmith JR, Borsa A. Optimization of legacy lidar data sets for measuring near-field earthquake displacements. Geophys Res Lett 2014;41:3494-501. doi:10.1002/2014GL059919.

Goodman A, Pepe A, Blocker AW, Borgman CL, Cranmer K, Crosas M, Di Stefano R, Gil Y, Groth P, Hedstrom M, Hogg DW, Kashyap V, Mahabal A, Siemiginowska A, Slavkovic A. Ten Simple Rules for the Care and Feeding of Scientific Data. PLoS Comput Biol 2014;10(4):e1003542. doi:10.1371/journal.pcbi.1003542.

Goodwell AE. Assessment of floodplain vulnerability during extreme Mississippi River flood 2011. Environ Sci Technol 2014;48:2619-25. doi:10.1021/es404760t.

Hamedianfar A, Shafri HZM, Mansor S, Ahmad N. Improving detailed rulebased feature extraction of urban areas from WorldView-2 image and lidar data. Int J Remote Sensing 2014;35(5):1876-99.

Hay GJ, Blaschke T, Marceau DJ, Bouchard A. A comparison of three imageobject methods for the multiscale analysis of lanscape structure. ISPRS J Photogramm 2003;57:327-45.

Hay GJ, Marceau DJ, Dubè P, Bouchard A. A multiscale framework for landscape analysis: Object-specific analysis and upscaling. Landscape ecol 2001;16:471-90.

Helbig N, Lowe H. Shortwave radiation parameterization scheme for subgrid topography. J Geophys Res-Atmos 2012;117(D3):1984-2012.

1415 Hensleigh J. Geomorphic Change Detection Using Multi-Beam SONAR. Technical Report; Utah State University; 2014. 
Heritage G, Hetherington D. Towards a protocol for laser scanning in fluvial geomorphology. Earth Surf Proc Land 2007;32:66-74. doi:10.1002/esp. 1375.

Heritage G, Large A. Laser Scanning for the Environmental Sciences. WileyBlackwell, 2009.

Hilley GE, Arrowsmith JR. Geomorphic response to uplift along the Dragons Back Pressure Ridge, Carrizo Plain, California. Geology 2008;36:367-70.

Hobi ML, Ginzler C. Accuracy assessment of digital surface models based on WorldView-2 and ADS80 stereo remote sensing data. Sensors 2012;12(5):6347-68. doi:10.3390/s120506347.

Hodgson ME, Jensen J, Raber G, Tullis J, Davis BA, Thompson G, Schuckman K. An evaluation of lidar-derived elevation and terrain slope in leaf-off conditions. Photogramm Eng Rem S 2005;71(7):817-23.

Hofmann P, Blaschke T, Strobl J. Quantifying the robustness of fuzzy rule sets in object-based image analysis. Int J Remote Sensing 2011;32(22):7359-81.

Hooke RL. On the efficacy of humans as geomorphic agents. GSA Today 1994;4(9).

Hooke RL. On the history of humans as geomorphic agents. Geology $2000 ; 28: 843-6$.

Hopkinson C, Chasmer LE, Sass G, Creed IF, Sitar M, Kalbfleisch W, Treitz P. Vegetation class dependent errors in lidar ground elevation and canopy height estimates in a boreal wetland environment. Ca J Remote Sens 2005;31(2):191206.

Howard A. A detachment-limited model of drainage basin evolution. Water 1440 Resour Res 1994;30 (7):2261-85.

Huang S, Young C, Feng M, Heidemann K, Cushing M, Mushet DM, Liu S. Demonstration of a conceptual model for using LiDAR to improve the esti- 
mation of floodwater mitigation potential of Prairie Pothole Region wetlands. J Hydrol 2011;405(3):417-26.

Hudak AT, Strand EK, Vierling LA, Byrne JC, Eitel JU, Martinuzzi S, Falkowski MJ. Quantifying aboveground forest carbon pools and fluxes from repeat LiDAR surveys. Remote Sens Environ 2012;123:25-40.

Hugenholtz CH, Whitehead K, Brown OW, Barchyn TE, Moorman BJ, LeClair A, Riddell K, Hamilton T. Geomorphological mapping with a small unmanned aircraft system (sUAS): Feature detection and accuracy assessment of a photogrammetrically-derived digital terrain model. Geomorphology 2013;194:16-24.

Ivanov VY, Bras RL, Vivoni ER. Vegetation-hydrology dynamics in complex terrain of semiarid areas: I. A mechanistic approach to modeling dynamic feedbacks. Water Resour Res 2008;44:W03429.

James MR, Robson S. Straightforward reconstruction of 3d surfaces and topography with a camera: Accuracy and geoscience application. J Geophys Res 2012;117:F03017. doi:10.1029/2011JF002289.

James MR, Robson S. Mitigating systematic error in topographic models derived from uav and ground-based image networks. Earth Surf Proc Land 2014;39:1413-20. doi:10.1002/esp.3609.

Javernick L, Brasington J, Caruso B. Modeling the topography of shallow braided rivers using structure-from-motion photogrammetry. Geomorphology 2014;213:166-82. doi:10.1016/j.geomorph.2014.01 .006.

Joerg PC, Morsdorf F, Zemp M. Uncertainty assessment of multi-temporal airborne laser scanning data: A case study on an Alpine glacier. Remote Sens Environ 2012;127:118-29. doi:10.1016/j.rse.2012.08.012.

Johnson K, Nissen E, Saripalli S, Arrowsmith JR, McGarey P, Scharer K, Williams P, Blisniuk K. Rapid mapping of ultrafine fault zone 
topography with structure from motion. Geosphere 2014;10(5):1-18. doi:10.1130/GES01017.1.

Kirkby M. Hillslope process-response models based on the continuity equation. Inst Brit Geogr, Spec Publ 1971;3:15-30.

Klapinski M, Hazel JE, Grams PE, Davis PA. Monitoring Fine-Sediment Volume in the Colorado River Ecosystem. ArizonaConstruction and Analysis of Digital Elevation Models Open File Report 2014-1052; U.S. Geological Survey; Grand Canyon Monitoring Research Center, Flagstaff, AZ; 2014. doi:10.3133/ofr20141052; 29pp.

Lague D, Brodu N, Leroux J. Accurate 3D comparison of complex topography with terrestrial laser scanner: Application to the Rangitikei canyon (N-Z). ISPRS J Photogramm 2013;82:10-26. doi:10.1016/j.isprsjprs. 2013.04.009.

Lane SN. Hydraulic modelling in hydrology and geomorphology: a review of high resolution approaches. Hydrol Process 1998;12:1131-50.

Lane SN, Chandler JH. Editorial: the next generation of high quality topographic data for hydrology and geomorphology: new data soures, new applications and new problems. Earth Surf Process Landforms 2003;28:229-30.

Lane SN, Westaway RM, Hicks DM. Estimation of erosion and deposition volumes in a large, gravel-bed, braided river using synoptic remote sensing. Earth Surf Process Landforms 2003;28:249-71. doi:10.1002/esp. 483.

Lashermes B, Foufoula-Georgiou E, Dietrich WE. Channel network extraction from high resolution topography using wavelets. Geophys Res Lett 2007;34:L23S04. doi:10 . 1029/2007GL031140.

Lefsky MA, Cohen WB, Parker GG, Harding DJ. Lidar remote sensing for ecosystem studies. Bioscience 2002;52(1):19-30. 
Legat K. Approximate direct georeferencing in national coordinates. ISPRS J Photogramm 2006;60:239-55. doi:10.1016/j.isprsjprs.2006.02.004.

Li J, Hu B, Noland TL. Classification of tree species based on structural features derived from high density LiDAR data. Agr Forest Meteorol 2013;171:104-14.

Lichti DD, Skaloud J. Registration and calibration. In: Airborne and Terrestrial laser scanning (edited by G. Vosselman and H.-G. Maas). CRC Press Inc; 2010. p. $83-133$.

Lucas Y. The role of plants in controlling rates and products of weathering: Importance of biological pumping. Annual Review of Earth and Planetary Sciences 2001;29:135-63. doi:10.1146/annurev.earth.29.1.135.

Mallet C, Bretar F. Full-waveform topographic lidar: State-of-the-art. ISPRS J Photogramm 2009;64:1-16.

Marcus WA, Fonstad MA. Remote sensing of rivers: the emergence of a subdiscipline in the river sciences. Earth Surf Process Landforms 2010;35:1867-72.

Marsh GP. Man and nature, or Physical geography as modified by human action. New York: C. Scribner \& Co., 1869. 577 pp.

Marsh GP. The Earth as modified by human action. New York: C. Scribner \& Co., 1882. 674 pp.

May C, Roering JJ, Eaton LS, Burnett KM. Controls on valley width in mountainous landscapes: The role of landsliding and implications for salmonid habitat. Geology 2013;41(4):503-6.

McKean J, Roering JJ. Objective landslide detection and surface morphology mapping using high-resolution airborne laser altimetry. Geomorphology 2004;57:331-51. doi:10.1016/S0169-555X (03) 00164-8.

1520

McKean J, Tonina D, Bohn C, Wright CW. Effects of bathymetric lidar errors on flow properties predicted with a multi-dimensional hydraulic model. J Geophys Res-Earth 2014;119(3):644-64. 
Meng X, Currit N, Zhao K. Ground filtering algorithms for airborne LiDAR data: a review of critical issues. Rem Sens 2010;2:833-60. doi:10.3390/rs2030833.

Meysman FJR, Middelburg JJ, Heip CHR. Bioturbation: a fresh look at darwin's last idea. Trends in Ecology and Evolution 2006;21:688-95. doi:10.1016/j.tree.2006.08.002.

Milan DJ, Heritage GL, Large ARG, Fuller IC. Filtering spatial error from DEMs: Implications for morphological change estimation. Geomorphology 2011;125(1):160-71. doi:10.1016/j.geomorph.2010.09.012.

Molotch NP, Painter TH, Bales RC, Dozier J. Incorporating remotely-sensed snow albedo into a spatially-distributed snowmelt model. Geophys Res Lett 2004;31(3):L03501. doi:10 . 1029/2003GL019063.

1535 Montgomery DR. Soil erosion and agricultural sustainability. Proc Nat Acad Sci 2007;104:13268-72.

Montgomery DR, Dietrich WE. Channel initiation, drainage density and slope. Water Resour Res 1989;25 (8):1907-18.

Morsdorf F, Nichol C, Malthus T, Woodhouse IH. Assessing forest structural 1540 and physiological information content of multi-spectral LiDAR waveforms by radiative transfer modelling. Remote Sens Environ 2009;113(10):2152-63.

Mountrakis G, Im J, Ogole C. Support vector machines in remote sensing: A review. ISPRS J Photogramm 2011;66:247-59. doi:10.1016/j.isprsjprs.2010.11.001.

1545 Mukoyama S. Estimation of ground deformation caused by the earthquake (Mw7.2) in Japan, 2008, from the geomorphic image analysis of high resolution LiDAR DEMs. J Mt Sci 2012;8:239-45.

Nguyen MQ, Atkinson PM, Lewis HG. Superresolution mapping using a Hopfield neural network with LIDAR data. IEEE Geosci Remote S 2005;2(3):3661550 70. 
Nissen E, Krishnan AK, Arrowsmith JR, Saripalli S. Three-dimensional surface displacements and rotations from differencing pre- and post-earthquake lidar point clouds. Geophys Res Lett 2012;39:L16301. doi:10.1029/2012GL052460.

Nissen E, Maruyama T, Arrowsmith JR, Elliott J, Krishnan A, Oskin M, Saripalli S. Coseismic fault zone deformation revealed with differential lidar: examples from japanese Mw7 intraplate earthquakes. Earth Planet Science Lett 2014;in review.

NRC . Elevation data for floodplain mapping. Washington, DC: The National Academies Press, 2007.

NRC . Landscapes on the edge. Washington, DC: The National Academies Press, 2010.

Oliver C, Quegan S. Understanding synthetic aperture radar images. SciTech Publishing, 2004. 512 pp.

Oskin ME, Arrowsmith JR, Corona AH, Elliott AJ, Fletcher JM, Fielding EJ, Gold PO, Gonzalez Garcia JJ, Hudnut KW, Liu-Zeng J, Teran OJ. Near-field deformation from the El Mayor-Cucapah earthquake revealed by differential lidar. Science 2012;335:702-5. doi:10.1126/science.1213778.

Paola C, Foufoula-Georgiou E, Dietrich WE, Hondzo M, Mohrig D, Parker G, Power ME, Rodriguez-Iturbe I, Voller V, Wilcock P. Toward a unified science of the Earth's surface: opportunities for synthesis among hydrology, geomorphology, geochemistry, and ecology. Water Resour Res 2006;42(3):W03S10. doi:10.1029/2005WR004336.

Passalacqua P, Belmont P, Foufoula-Georgiou E. Automatic geomorphic feature extraction from lidar in flat and engineered landscapes. Water Resour Res 2012;48:W03528. doi:10.1029/2011WR010958.

Passalacqua P, Tarolli P, Foufoula-Georgiou E. Testing space-scale methodologies for automatic geomorphic feature extraction from lidar in a 
complex mountainous landscape. Water Resour Res 2010b;46:W11535. doi:10.1029/2009WR008812.

Passalacqua P, Trung TD, Foufoula-Georgiou E, Sapiro G, Dietrich WE. A geometric framework for channel network extraction from lidar: Nonlinear diffusion and geodesic paths. J Geophys Res 2010a;115:F01002. doi:10.1029/2009JF001254.

Pelletier JD. A robust, two-parameter method for the extraction of drainage networks from high-resolution digital elevation models (dems): Evaluation using synthetic and real-world networks. Water Resour Res 2013;49:1-15. doi:10.1029/2012WR012452.

Pelletier JD, Orem CA. How do sediment yields from post-wildfire debris-laden flows depend on terrain slope, soil burn severity class, and drainage basin area? Insights from airborne-LiDAR change detection. Earth Surf Process Landforms 2014;doi:10.1002/esp. 3570.

Perona P, Malik J. Scale-space and edge detection using anisotropic diffusion. IEEE-PAMI 1990;12:629-39.

Perron JT, Kirchner JW, Dietrich WE. Formation of evenly spaced ridges and valleys. Nature 2009;460:502-5. doi:10.1038/nature08174.

Petrie G, Toth CK. Introduction to laser ranging, profiling and scanning. In: Shan J, Toth CK, editors. Topographic Laser Ranging and Scanning: Principles and Processing. Boca Raton, FL: CRC Press; 2009a. p. 1-27.

Petrie G, Toth CK. Terrestrial laser scanners. In: Shan J, Toth CK, editors. Topographic Laser Ranging and Scanning: Principles and Processing. Boca Raton, FL: CRC Press; 2009b. p. 87-127.

Petrie G, Toth CK. Airborne and spaceborne laser profilers and scanners. In: Shan J, Toth CK, editors. Topographic Laser Ranging and Scanning: Principles and Processing. Boca Raton, FL: CRC Press; 2009c. p. 29-85. 
Pfeifer N, Mandlburger G. LiDAR data filtering and DTM generation. In: Shan J, Toth CK, editors. Topographic Laser Ranging and Scanning: Principles and Processing. Boca Raton, FL: CRC Press; 2009. p. 308-33.

Phillips JD. Biological energy in landscape evolution. American Journal of Science 2009;309:271-89. doi:10.2475/04.2009.01.

Pike RJ, Evans IS, Hengl T. Geomorphometry: a brief guide. In: Hengl T, Reuter H, editors. Geomorphometry: concepts, software, applications. Elsevier; volume 33; 2009. p. 3-30.

Priestnall G, Jaafar J, Duncan A. Extracting urban features from LIDAR digital surface models. Comput Environ Urban 2000;24:65-78.

Reed S, Amundson R. Using LIDAR to model Mima mound evolution and regional energy balances in the Great Central Valley, California. Geol S Am S 2012;490:21-41.

Reinhardt L, Jerolmack D, Cardinale BJ, Vanacker V, Wright J. Dynamic interactions of life and its landscape: feedbacks at the interface of geomorphology and ecology. Earth Surf Process Landforms 2010;35(1):78-101.

Renslow M. Manual of Airborne Topographic LiDAR. Bethesda, MD: American Society for Photogrammetry and Remote Sensing, 2012. 504 pp.

Rhoads BL. The Dynamic Basis of Geomorphology Reenvisioned. Annals of the Association of American Geographers 2006;96(1):14-30.

Riitters KH, Wickham JD. How far to the nearest road? Front Ecol Environ 2003;1(3):125-9.

Roering J. How well can hillslope evolution models 'explain' topography? simulating soil transport and production with high-reolution topographic data. Geol Soc Am Bull 2008;120 (9):1248-62. 
Roering J, Kirchner J, Dietrich W. Evidence for nonlinear, diffusive sediment transport on hillslopes and implications for landscape morphology. Water Resour Res 1999;35:853-70.

Roering J, Mackey BH, Marshall JA, Sweeney KE, Deligne NI, Booth AM, Handwerger AL, Cerovski-Darriau C. You are HERE: Connecting the dots with airborne lidar for geomorphic fieldwork. Geomorphology 2013;200:17283.

Roering J, Marshall J, Booth AM, Mort M, Jin Q. Evidence for biotic controls on topography and soil production. Earth Planet Sci Lett 2010;298(1):183-90.

Roering J, Stimely LL, Mackey BH, Schmidt DA. Using DInSAR, airborne LiDAR, and archival air photos to quantify landsliding and sediment transport. Geophys Res Lett 2009;36:L19402. doi:10.1029/2009\{GL\}040374.

Rosser NJ, Petley DN, Lim M, Dunning SA, Allison RJ. Terrestrial laser scanning for monitoring the process of hard rock coastal cliff erosion. Q J Eng Geol Hydroge 2005;38:363-75.

Schaer P, Skaloud J, Landtwig S, Legat K. Accuracy estimation for laser point cloud including scanning geometry. In: Proc. of the 5th international symposium on Mobile Mapping Technology. Padua, Italy; 2007. .

Schmidt J, Andrew R. Multi-scale landform characterization. Area $2005 ; 37(3): 341-50$.

Schmidt J, Hewitt A. Fuzzy land element classification from dtms based on geometry and terrain position. Geoderma 2004;121(3):243-56.

Schurch P, Densmore AL, Rosser NJ, Lim M, McArdell BW. Detection of surface change in complex topography using terrestrial laser scanning: application to the Illgraben debris-flow channel. Earth Surf Process Landforms 2011;36:1847-59. doi:10.1002/esp. 2206. 
Shan J, Toth C. Topographic Laser Ranging and Scanning. New York, NY: CRC Press, 2009. 504 pp.

Sidle RC, Noguchi S, Tsuboyama Y, Laursen K. A conceptual model of preferential flow systems in forested hillslopes: evidence of self-organization. Hydrol Process 2001;15:1675-92. doi:10.1002/hyp. 233.

Sidle RC, Ziegler AD. The dilemma of mountain roads. Nature Geoscience $2012 ; 5: 437-8$.

Sithole G, Vosselman G. Experimental comparison of filter algorithms for bareEarth extraction from airborne laser scanning point clouds. ISPRS J Photogramm 2004;59:85-101.

Smith T, Bretherton F. Stability and the conservation of mass in drainage basin evolution. Water Resour Res 1972;8:1506-29.

Snavely N. Scene reconstruction and visualization from Internet photo collections. Ph.D. thesis; University of Washington, USA; 2008.

Sofia G, Pirotti F, Tarolli P. Variations in multiscale curvature distribution and signatures of LiDAR DTMs errors. Earth Surf Proc Land 2013;38(10):111634. doi:10.1002/esp. 3363.

Sofia G, Tarolli P, Cazorzi F, Dalla Fontana G. An objective approach for feature extraction: distribution analysis and statistical descriptors for scale choice and channel network identification. Hydrol Earth Syst Sc 2011;15:1387402. doi:10.5194/hess-15-1387-2011.

Soudarissanane S, Lindenbergh R, Menenti M, Teunissen P. Scanning geometry: Influencing factor on the quality of terrestrial laser scanning points. ISPRS J Photogramm 2011;66(4):389-99. doi:10.1016/j . isprsjprs.2011.01.005. and slope effects on accuracy of a LiDAR-derived DEM in the sagebrush steppe. Remote Sens Lett 2011;2(4):317-26. 
Stout J, Belmont P. TerEx Toolbox for semi-automated selection of fluvial terrace and floodplain features from lidar. Earth Surf Proc Land 2014;39(5):56980. doi:10.1002/esp. 3464 .

Strahler AN. Dynamic basis of geomorphology. Bulletin of the Geological Society of America 1952;63:923-38.

Streutker D, Glenn N. Lidar measurement of sagebrush steppe vegetation heights. Remote Sens Environ 2006;102:135-45. doi:10.1016/j.rse.2006.02.011.

Streutker D, Glenn N, Shrestha R. A slope-based method for matching elevation surfaces. Photogramm Eng Rem S 2011;77(7):743-50.

Stumpf A, Malet J, Allemand P, Ulrich P. Surface reconstruction and landslide displacement measurements with pléiades satellite images. ISPRS J Photogramm 2014;95:1-12. doi:10.1016/j.isprsjprs.2014.05.008.

Suárez JC, Ontiveros C, Smith S, Snape S. Use of airborne LiDAR and aerial photography in the estimation of individual tree heights in forestry. Comp Geosci 2005;31:253-62. doi:10.1016/j.cageo.2004.09.015.

Syvitski JPM, Saito Y. Morphodynamics of deltas under the influence of humans. Glob Planet Change 2007;57:261-82.

Tarolli P. High-resolution topography for understanding Earth surface processes: Opportunities and challenges. Geomorphology 2014;216:295-312.

Tarolli P, Preti F, Romano N. Terraced landscapes: from an old best practice to a potential hazard for soil degradation due to land abandonment. Anthropocene 2014;doi:10.1016/j. ancene.2014.03.002.

Tarolli P, Sofia G, Dalla Fontana G. Geomorphic features extraction from high-resolution topography: landslide crowns and bank erosion. Nat Hazards 2012;61:65-83. doi:10.1007/s11069-010-9695-2. 
Taylor J. An Introduction to Error Analysis: the Study of Uncertainties in Physical Measurements, Second Edition. Sausalito, California: University Science Books, 1997. 327 pp.

Teza G, Galgaro A, Zaltron N, Genevois R. Terrestrial laser scanner to detect landslide displacement fields: a new approach. Int J Remote Sens 2007;28(16):3425-46. doi:10.1080/01431160601024234.

1715 Tinkham WT, Huang H, Smith AMS, Shresta R, Falkowski MJ, Hudak AT, Link TE, Glenn NF, Marks DG. A comparison of two open source lidar surface classification algorithms. Remote Sens 2011;3:638-49. doi:doi: 10.3390/rs3030638.

Tomer MD, Crumpton WG, Bingner RL, Kostel JA, James DE. Estimating nitrate load reductions from placing constructed wetlands in a HUC-12 watershed using LiDAR data. Ecol Eng 2013;56:69-78.

Trimble SW. Decreased rates of alluvial sediment storage in the Coon Creek Basin, Wisconsin, 1975-93. Science 1999;285:1244-6. doi:10.1126/science.285.5431.1244.

1725 Tucker GE, Bradley DN. Trouble with diffusion: reassessing hillslope erosion laws with a particle-based model. J Geophys Res 2010;115:F00A10. doi:10.1029/2009JF001264.

Tucker GE, Slingerland RL. Erosional dynamics, flexural isostacy, and long-lived escarpments: a numerical modeling study. J Geophys Res 1994;99 (12):22912.

Tucker GE, Slingerland RL. Drainage basin responses to climate change. Water Resour Res 1997;33:2031-47.

Turner D, Lucieer A, Watson C. An automated technique for generating georectified mosaics from ultra-high resolution Unmanned Aerial Vehicles (UAV) ${ }_{1735}$ imagery, based on Structure from Motion (SfM) point clouds. Remote Sens 2012;4:1392-410. doi:10.3390/rs4051392. 
Vaaja M, Hyyppä J, Kukko A, Kaartinen H, Hyyppä H, Alho P. Mapping topography changes and elevation accuracies using a mobile laser scanner. Remote Sens 2011;3(3):587-600. doi:10.3390/rs3030587.

${ }_{1740}$ Vierling KT, Vierling LA, Gould WA, Martinuzzi S, Clawges RM. Lidar: shedding new light on habitat characterization and modeling. Front Ecol Environ $2008 ; 6(2): 90-8$.

Vosselmann G, Maas HG. Airborne and Terrestrial Laser Scanning. New York, NY: CRC Press, 2010. 318 pp.

Wasklewicz T, Staley DM, Reavis K, Oguchi T. Digital terrain modeling. In: Shroder J, Bishop MP, editors. Treatise on Geomorphology. San Diego, CA: Academic Press; volume 3; 2013. p. 130-61.

Westoby MJ, Brasington J, Glasser NF, Hanbrey MJ, Reynolds JM. 'Structure-from-Motion' photogrammetry: a low-cost, effective tool for geoscience applications. Geomorphology 2012;179:300-14. doi:10.1016/j.geomorph.2012.08.021.

Wheaton JM, Brasington J, Darby SE, Kasprak A, Sear DA, Vericat D. Morphodynamic signatures of braiding mechanisms as expressed through change in sediment storage in a gravel-bed river. J Geophys Res Earth Surf 2013;118:759-79. doi:10.1002/jgrf. 20060.

Wheaton JM, Brasington J, Darby SE, Sear DA. Accounting for uncertainty in DEMs from repeat topographic surveys: improved sediment budgets. Earth Surf Process Landforms 2010;35:136-56. doi:10.1002/esp. 1886.

Wheaton JM, Darby SE, Sear DA. The scope of uncertainties in river restoration. In: Darby SE, Sear D, editors. River Restoration: Managing the Uncertainty in Restoring Physical Habitat. Chichester, U.K.: John Wiley and Sons; 2008. p. 21-39. doi:10.1002/9780470867082.ch3. 
White EP, Baldridge E, Brym ZT, Locey KJ, McGlinn DJ, Supp SR. Nine simple ways to make it easier to (re)use your data. PeerJPrePrints 2013;1:e7v2. Http://dx.doi.org/10.7287/peerj.preprints.7v2.

Wiener N. Extrapolation, Interpolation, and Smoothing of Stationary Time Series. New York: Wiley, 1949.

Wilkinson BH, McElroy BJ. The impact of humans on continental erosion and sedimentation. Geol Soc Am Bull 2007;119:140-56.

1770 Willgoose G, Bras R, Rodriguez-Iturbe I. A coupled channel network growth and hillslope evolution model; 1, theory. Water Resour Res 1991a;27:1671-84.

Willgoose G, Bras R, Rodriguez-Iturbe I. A coupled channel network growth and hillslope evolution model; 2, nondimensionalization and application. Water Resour Res 1991b;27:1685-96.

Willgoose G, Bras R, Rodriguez-Iturbe I. A physical explanation of an observed link area-slope relationship. Water Resour Res 1991c;27:1697-702.

Williams K, Olsen MJ, Roe GV, Glennie C. Synthesis of transportation applications of mobile lidar. Remote Sens 2013;5:4652-92. doi:doi : 10.3390/rs5094652.

Williams RD, Brasington J, Vericat D, Hicks DM. Hyperscale terrain modelling of braided rivers: fusing mobile terrestrial laser scanning and optical bathymetric mapping. Earth Surf Process Landforms 2014;39:167-83. doi:doi : 10.1002/esp. 3437.

Yoo K, Amundson R, Heimsath AM, Dietrich WE. Process-based model linking pocket gopher (Thomomys bottae) activity to sediment transport and soil thickness. Geology 2005;33(11):917-20. doi:10.1130/G21831.1.

Yoo K, Weinman B, Mudd SM, Hurst M, Attal M, Maher K. Evolution of hillslope soils: The geomorphic theater and the geochemical play. Appl Geochem 2011;26:S149-53. 

structure with lidar composite metrics and machine learning. Remote Sens Environ 2011;115:1978-96. doi:10.1016/j.rse.2011.04.001.

Zhao K, Popescu SC, Zhang X. Bayesian learning with gaussian processes for supervised classification of hyperspectral data. Photogramm Eng Rem S 2008;74(10):1223-34. 


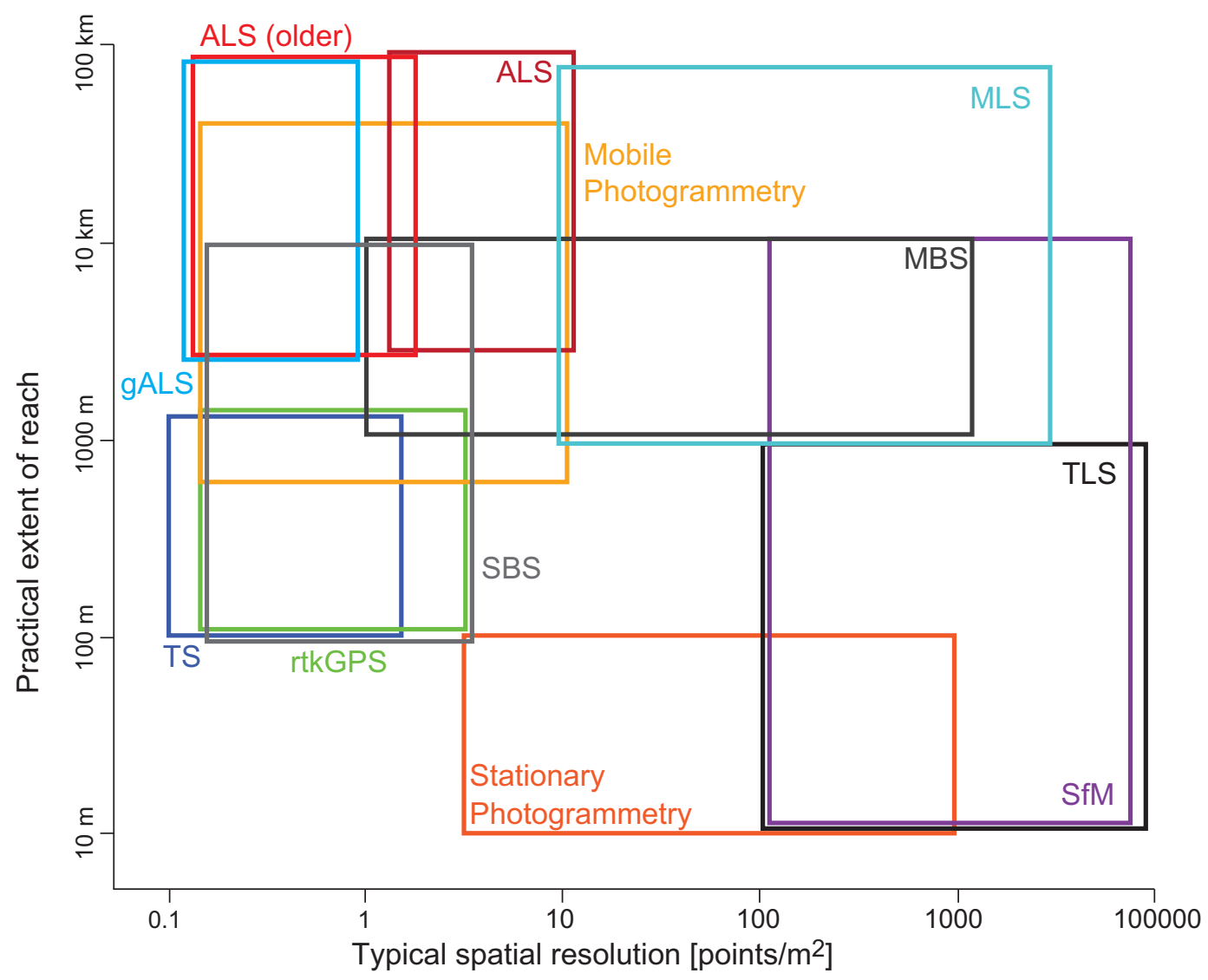

Figure 1: Diagram of typical spatial resolution versus practical extent of analysis reach for Airborne Laser Scanning (ALS), green ALS (gALS), Mobile Laser Scanning (MLS), Total Station (TS), real time kinematic GPS (rtkGPS), single-beam SONAR (SBS), multibeam SONAR (MBS), stationary and mobile photogrammetry, Structure from Motion (SfM), and Terrestrial Laser Scanning (TLS). Figure modified from Bangen et al. (2014). 


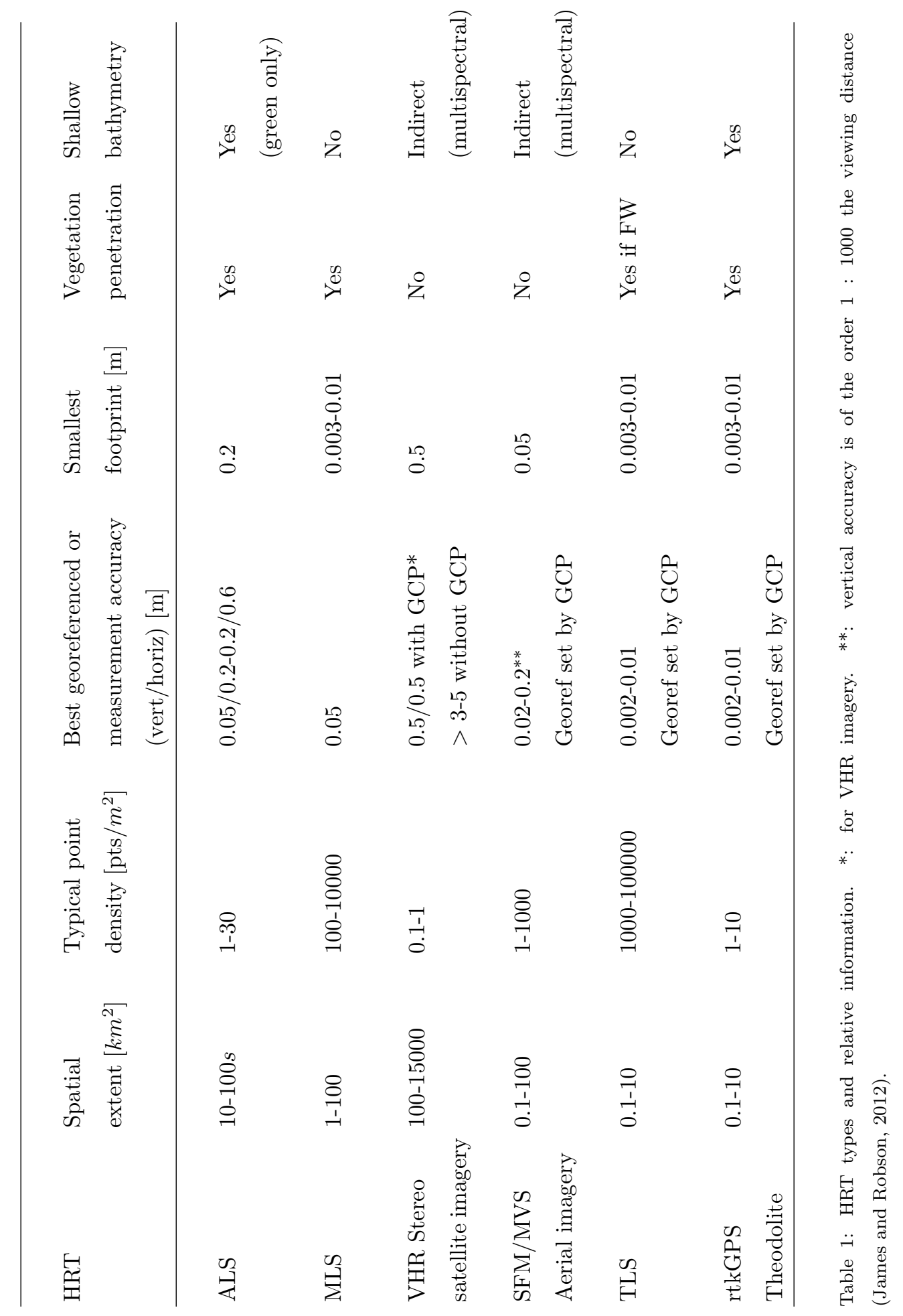




\section{a Airborne LiDAR}

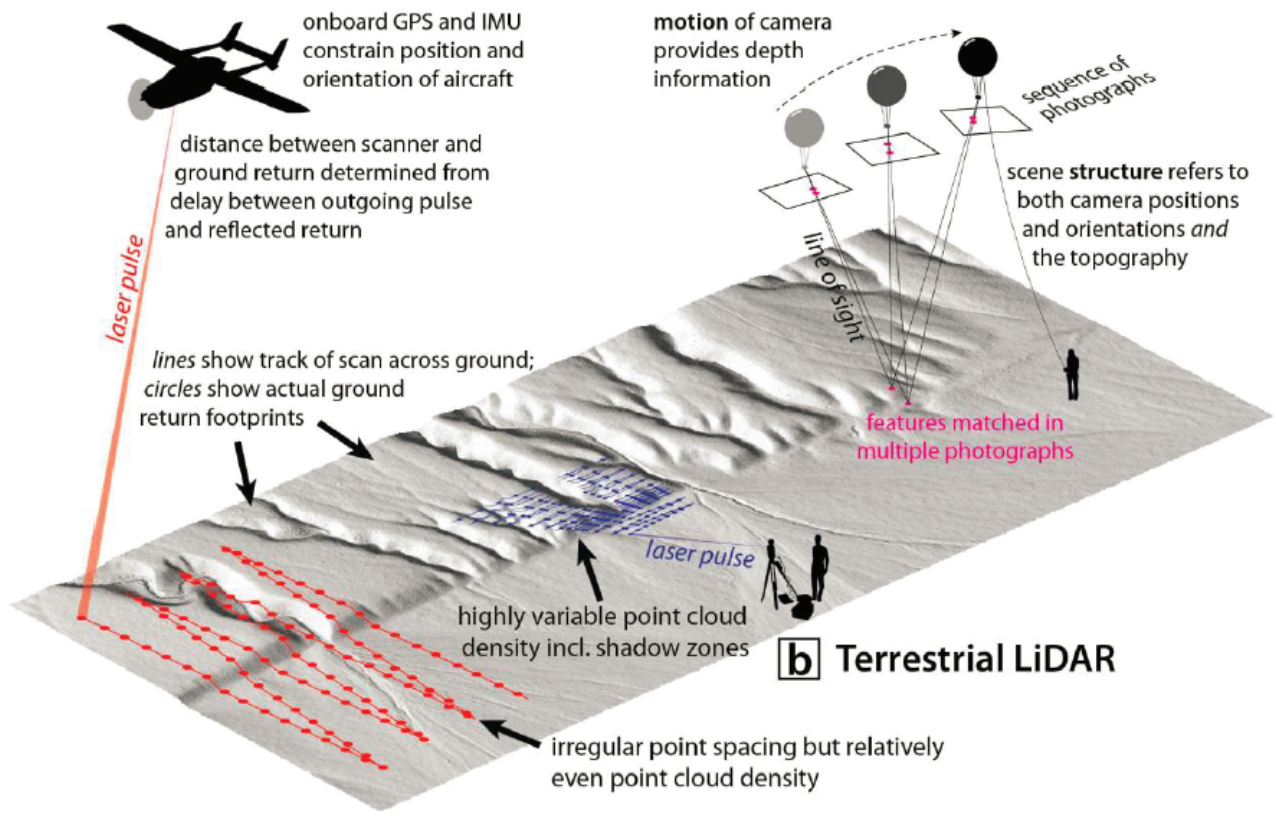

Figure 2: Comparison of raw data acquisition from ALS (a), TLS (b), and SfM (c). Figure reproduced from Johnson et al. (2014). 


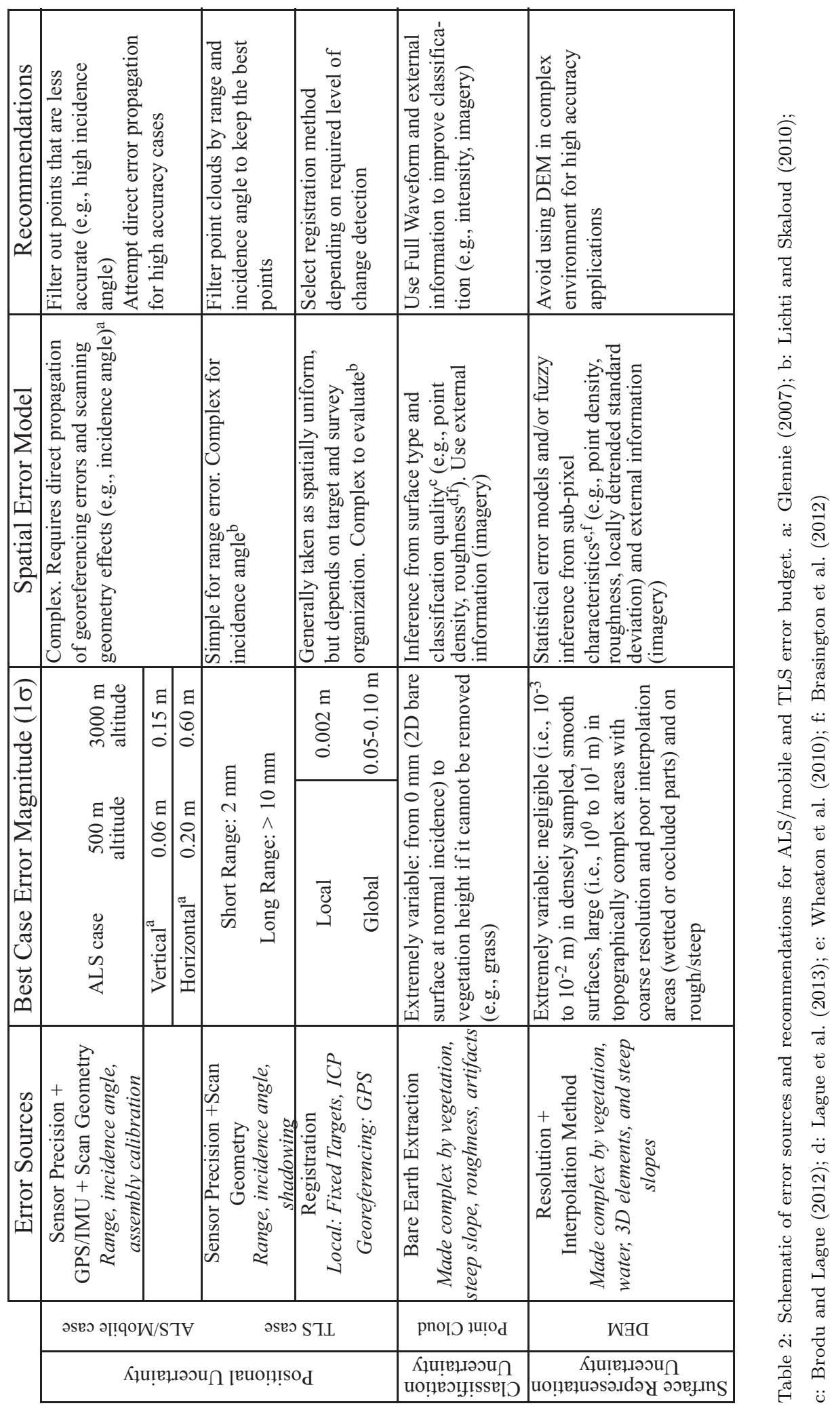




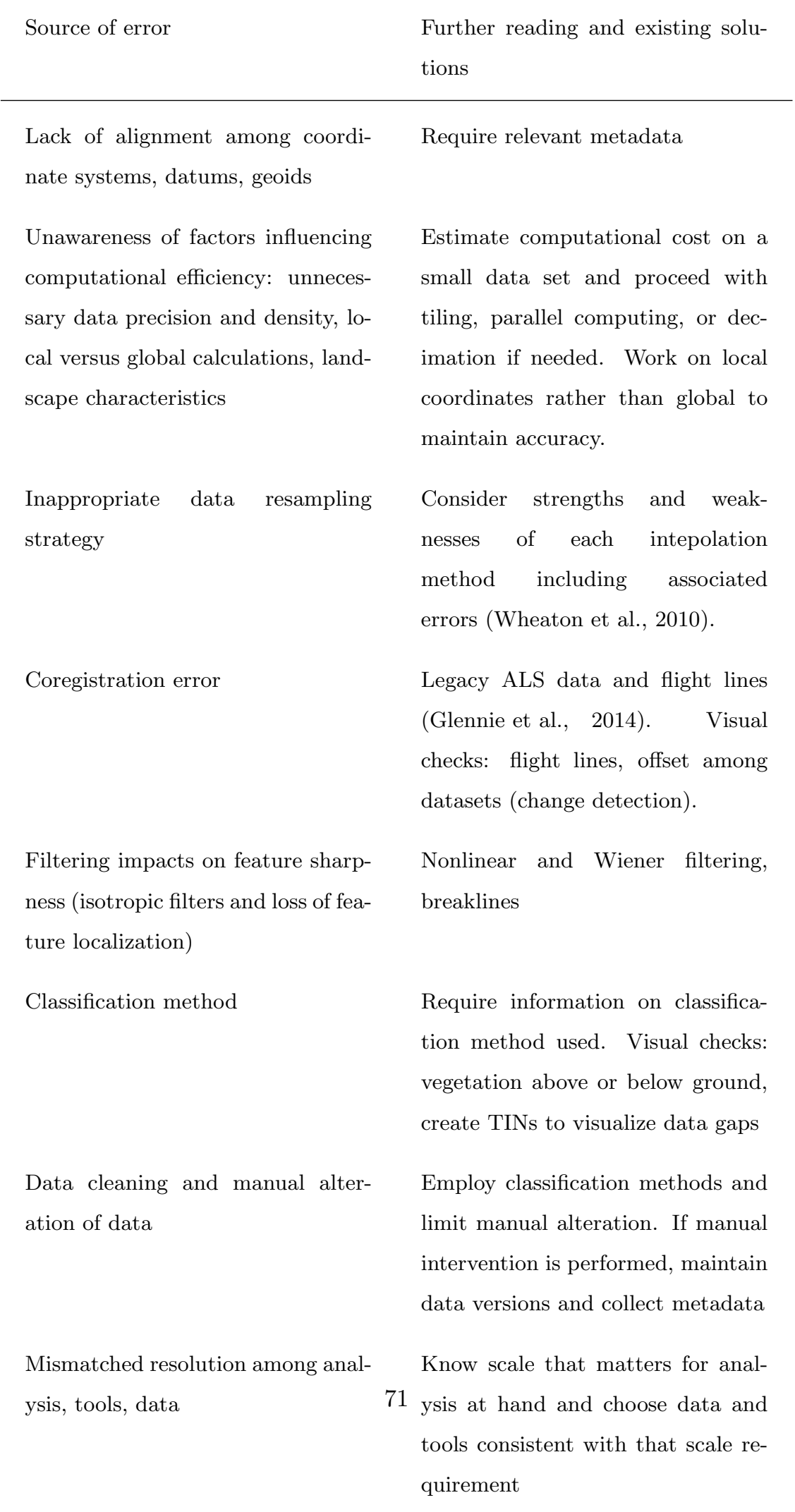

Table 3: Common sources of error in HRT data analysis and references for further reading and existing solutions. See also text for additional discussion on each point. 


\section{Box 1: Questions to consider before acquiring HRT}

1) Specification Document: Should a specification document be written to define minimum requirements, deliverables, and answers to the following questions?

2) HRT Method: What HRT acquisition method(s) would allow collection of the data?

3) Who acquires HRT: Will a vendor be employed, will you be responsible for data collection, or will the responsibility be shared? 4) Acquisition Timing: When should acquisition be scheduled to maximize likelihood of successful and useful data collection? Considerations include: season, antecedent moisture or flow levels (rivers), vegetative cover (e.g., leaf on vs. leaf off)

5) Hybrid Data: Will the HRT dataset need to be meshed with other topographic data to paint a complete picture of the study area? How will continuity among datasets be ensured?

6) Acquisition Perspective: How will scans (e.g., flight lines, TLS scans, photo orientation, boat paths) be oriented relative to features of interest?

7) Overlapping Coverage: How much overlap is needed between scans to obtain the needed point cloud density? Does increased density from overlapping coverage constrain HRT models or present conflicting evidence uncertainties?

8) Accuracy Assessment: What independent data (e.g., check points, check surfaces, other methods of acquisition, air photos) are available in the area or should be collected concurrently for verification and accuracy assessment?

9) Accuracy and Precision Specifications: What point cloud density or vertical and horizontal accuracy are needed to answer the question of interest?

10) Cost-Benefit: Are there inflections in the cost/data characteristics relationships that would make additional data collection feasible with current project budget?

11) Features of Interest: What are the features of interest where the best quality information is needed? Is penetration through water or dense vegetation needed?

12) Breaklines: How and where will breaklines be used to ensure that critical features/boundaries are well defined?

13) Coordinate Systems and Control Network: Do data need to be referenced to a local or global coordinate system (i.e. georeferenced)? Is an adequate existing control network in place to facilitate this or does one need to be established or modified? Is it necessary to hire a professional surveyor to establish and improve the network?

12) Repeat Survey Planned or Plausible: Will the data be compared to future surveys? Even if not planned, but plausible future use by others, is the control network sufficiently redundant to facilitate future repeat occupation of the control network?

13) Uncertainty: What factors contribute to spatially variable uncertainty of the dataset (e.g., shadows, angle of incidence)? 14) Output Formats: What are the required end product deliverable format(s) for the post-processed HRT data (e.g., classified point cloud, bare earth point cloud, TIN, raster)?

15) Reporting and Data Sharing: What level of metadata documentation and reporting will be necessary to make the data useful for its current purposes and to other potential end-users? Do deliverable outputs need to be shared with others and how will this be achieved?

16) Post-Processing: What post-processing steps will be needed for the data to be useful for your putipposes (e.g., filtering, interpolation)? Will the vendor or user complete those steps? If performed by 


\section{Box 2: Questions to consider before analyzing new or existing HRT}

1) Metadata Report: Does a metadata report exist that documents answers to the following questions?

2) Acquisition Timing: When were the data collected?

3) Coordinate Systems: If comparing to other data, are coordinate systems and reference GEOIDS consistent? In which datum, coordinate system, and GEOID were the data originally collected? Is re-projection of the data required? If so, is re-projecting the point cloud instead of the derivative surfaces desirable?

4) Hybrid Dataset: Do the data contain multiple HRT types that have been stitched together?

5) Format: What data formats are available (e.g., LAS, raw point cloud, classified point cloud, TIN, DEM)?

6) Post-Processing: What filters, corrections, and modifications were applied to the data to convert it from raw data to its current state?

7) Blunders and Busts: Are there artifacts in the dataset? How to deal with them? Are there portions of the dataset that are of especially high or low quality?

8) Validation/Verification: Are validation/verification data available? Is information available for constraining vertical and horizontal error? Is the collection of additional verification data needed to determine whether the quality of the data is sufficient to answer the question of interest?

9) Analysis Methods: What are the most appropriate methods and protocols for processing and analyzing the data? Is the implementation of these methods and associated computational costs within 

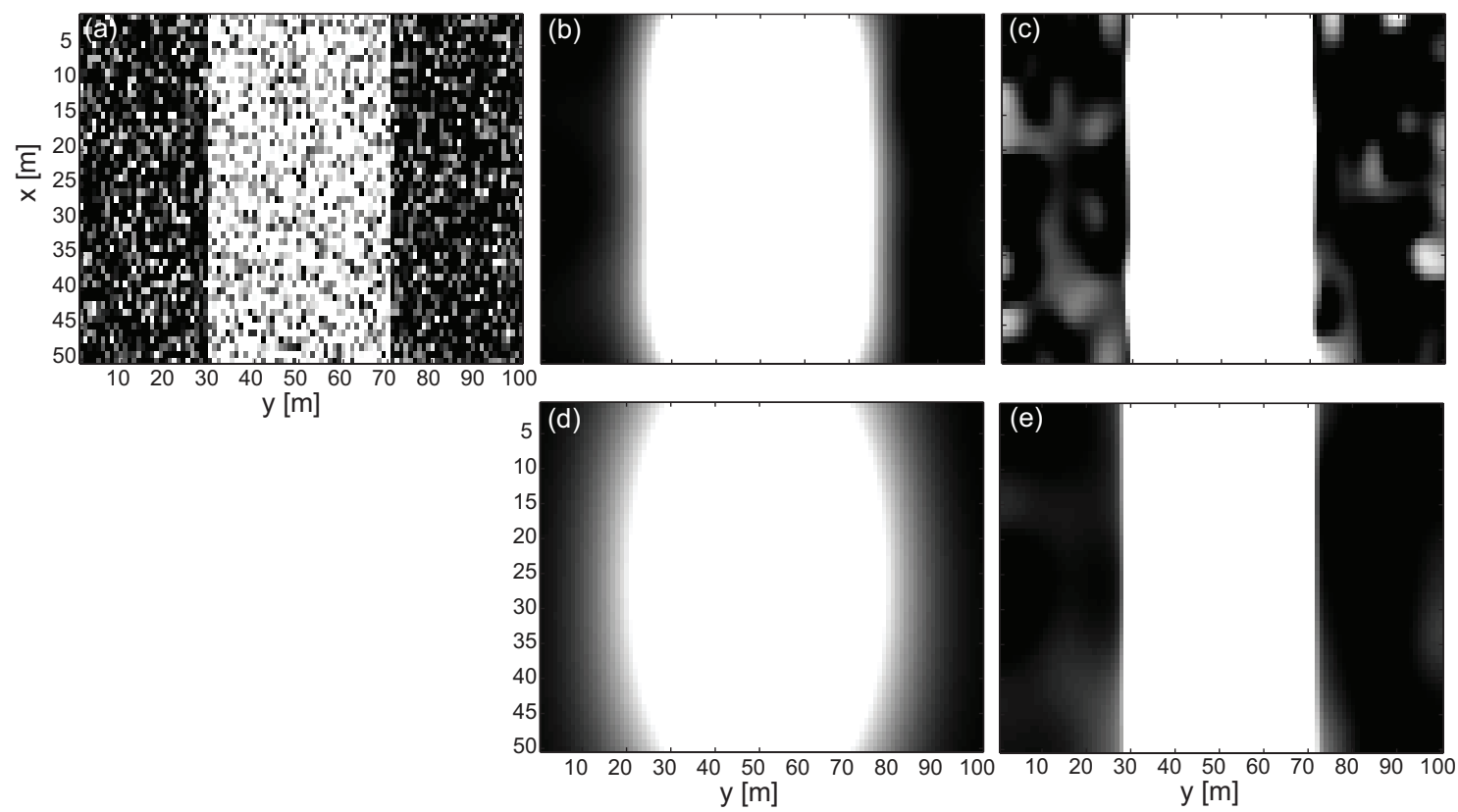

Figure 3: Comparison of the performance of Gaussian (linear) and Perona-Malik (nonlinear) filtering on an idealized landscape with added noise. The white portion is at higher elevation (ridge) than the surrounding landscape. (a) Original noisy image; (b) Noise reduction achieved by Gaussian filtering (standard deviation of the kernel $7 \mathrm{~m}$ ) at the expense of the boundaries localization; (c) Noise reduction achieved by Perona-Malik filtering (number of iterations $\mathrm{t}=50$ ). The filter is able to preserve feature localization by avoiding diffusion across its boundaries; (d) Further noise reduction with Gaussian filtering (14 m) results in complete blurring of the ridge; (e) Further Perona-Malik filtering $(t=200)$ results in more noise reduction without affecting the feature and its localization. Figure adapted from Passalacqua et al. (2010a). 


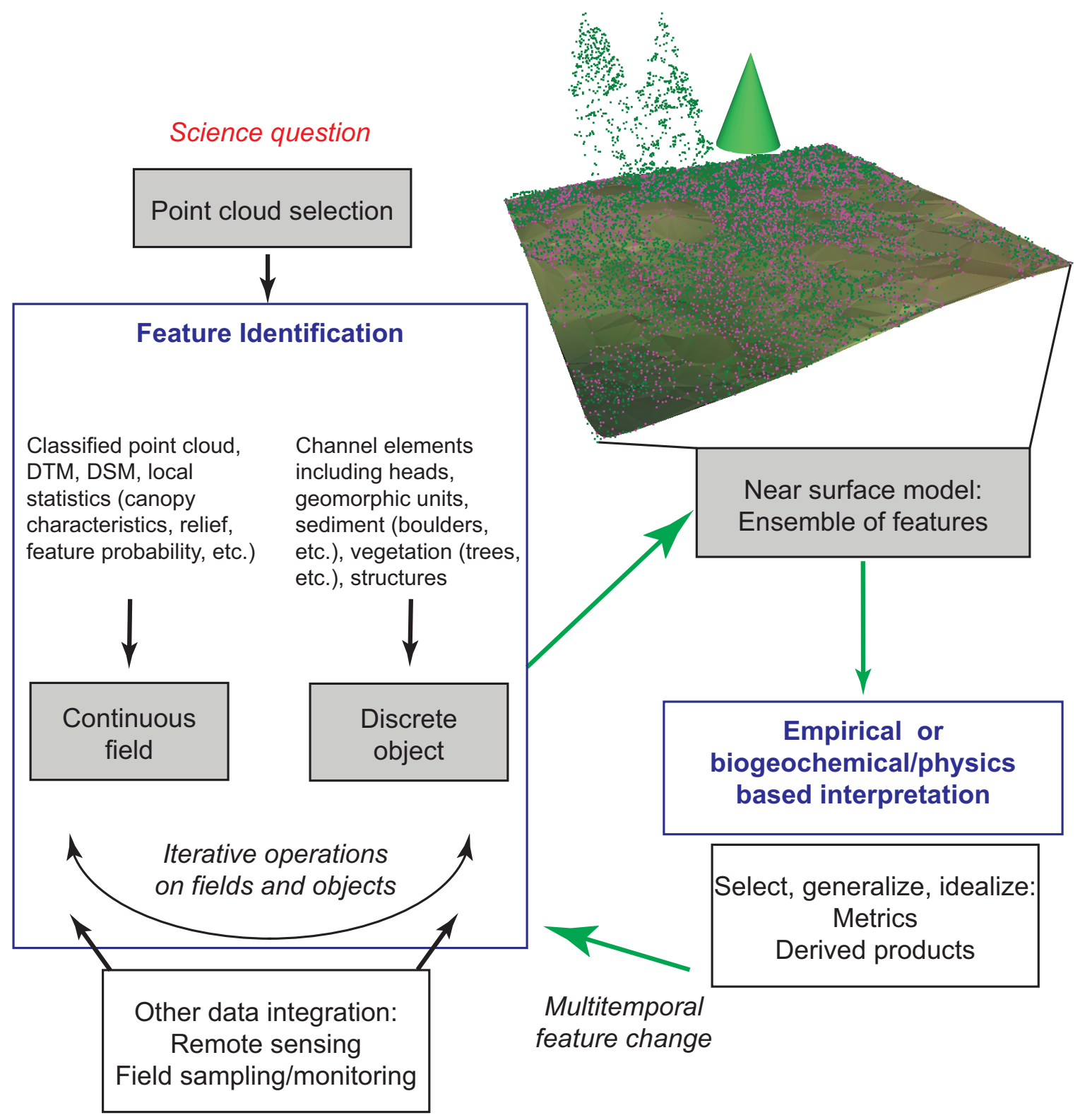

Figure 4: Feature identification work-flow. Principal tasks are to progressively add meaning to a segmented point cloud by identifying continuous fields or discrete objects. The ensemble of identified features is the near surface model and is the basis for scientific interpretation or engineering application. Changes in the near surface model may further indicate process. See text for additional explanation. 
Type of geometric change

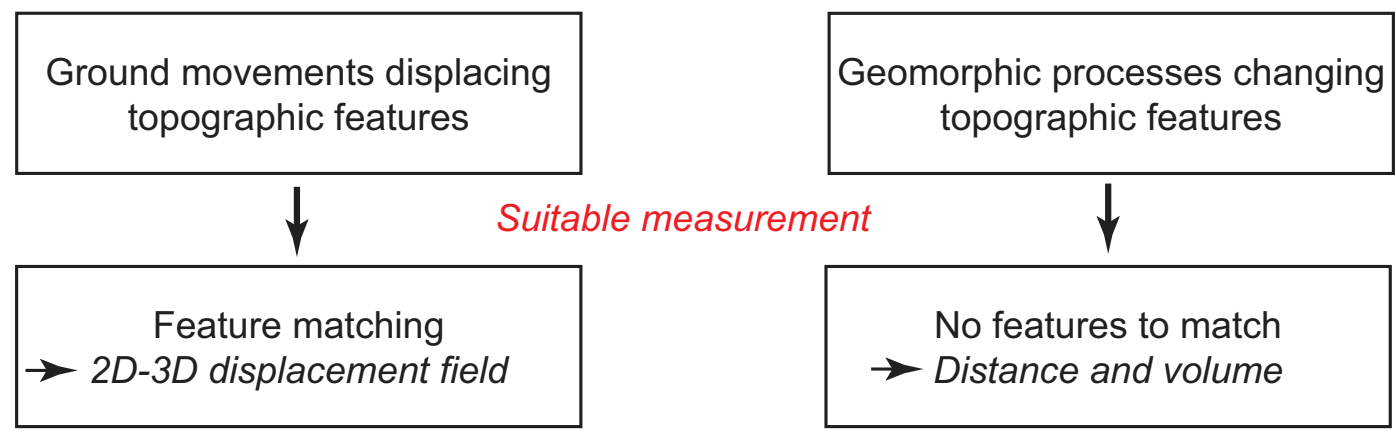

Existing automatic work-flows
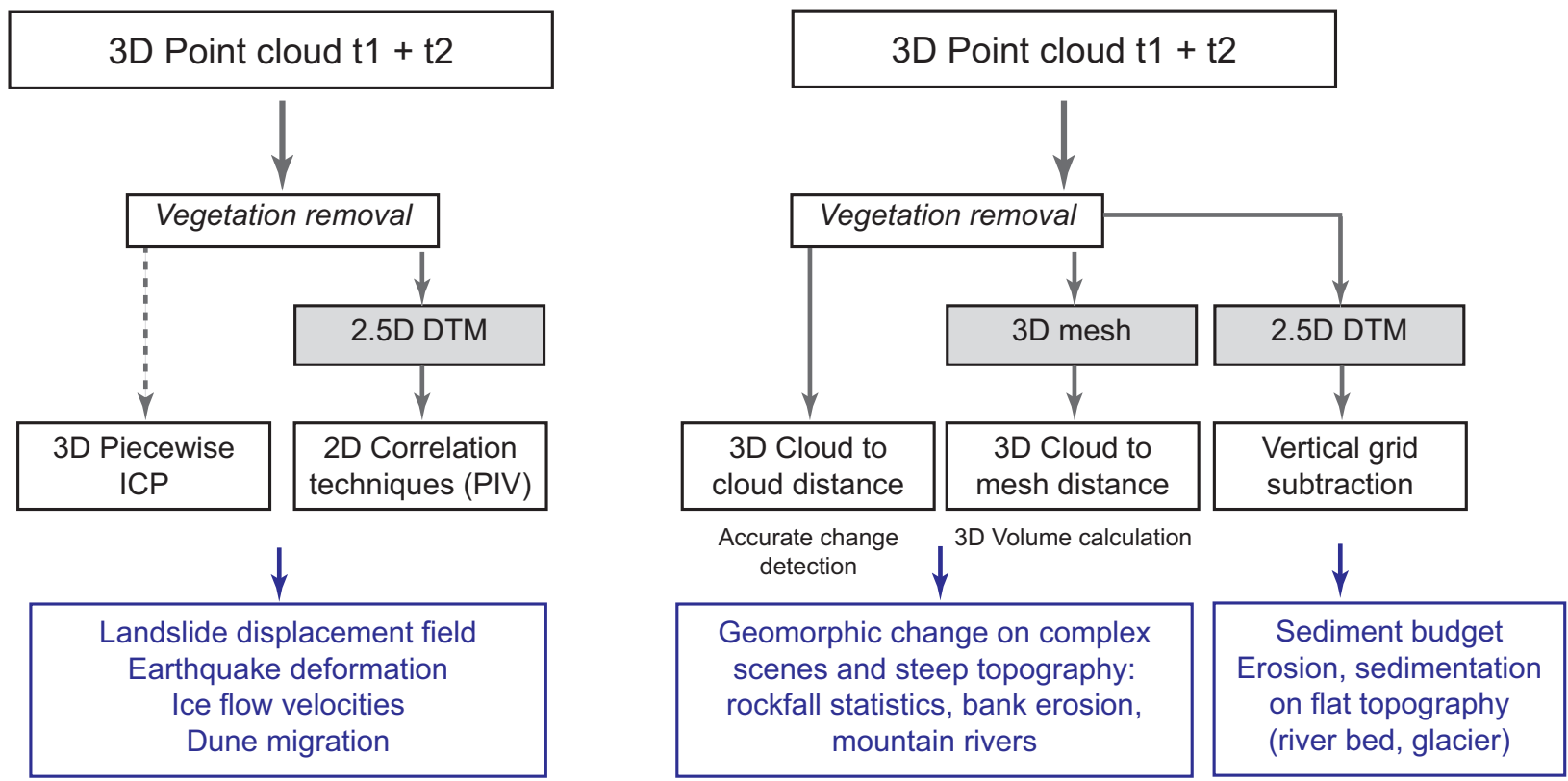

Figure 5: Schematic of work-flows for change detection. Solid gray arrows indicate operations for which fully open source solutions exist; dashed gray arrows indicate operations that require at least one commercial software; blue boxes show examples of products obtainable with each work-flow. Gray filled boxes indicate operations producing a product easier to handle but interpolated resulting in potential accuracy and resolution loss. 